\title{
OECD Statistics Working Papers 2016/01
}

\author{
Where is inclusive growth \\ happening? Mapping multi- \\ dimensional living standards \\ in OECD regions
} Paolo Veneri, 
Organisation de Coopération et de Développement Économiques

Organisation for Economic Co-operation and Development

16-Feb-2016

STATISTICS DIRECTORATE

English - Or. English

WHERE IS INCLUSIVE GROWTH HAPPENING? MAPPING MULTI-DIMENSIONAL LIVING STANDARDS IN OECD REGIONS

\section{WORKING PAPER No.67}

Contact: Paolo Veneri, Directorate for Governance and Territorial Development, +(33-1) 452481 38, Paolo.VENERI@oecd.org ; Fabrice Murtin, Statistics Directorate, +(33-1) 452476 08;

Fabrice.MURTIN@oecd.org

\section{JT03390175}

Complete document available on OLIS in its original format

This document and any map included herein are without prejudice to the status of or sovereignty over any territory, to the delimitation of international frontiers and boundaries and to the name of any territory, city or area. 
STD/DOC(2016)1

WHERE IS INCLUSIVE GROWTH HAPPENING?

MAPPING MULTI-DIMENSIONAL LIVING STANDARDS IN OECD REGIONS

Paolo Veneri and Fabrice Murtin 


\section{OECD STATISTICS WORKING PAPER SERIES}

The OECD Statistics Working Paper Series - managed by the OECD Statistics Directorate - is designed to make available in a timely fashion and to a wider readership selected studies prepared by OECD staff or by outside consultants working on OECD projects. The papers included are of a technical, methodological or statistical policy nature and relate to statistical work relevant to the Organisation. The Working Papers are generally available only in their original language - English or French - with a summary in the other.

OECD Working Papers should not be reported as representing the official views of the OECD or of its member countries. The opinions expressed and arguments employed are those of the author

Working Papers describe preliminary results or research in progress by the author and are published to stimulate discussion on a broad range of issues on which the OECD works. Comments on Working Papers are welcomed, and may be sent to the Statistics Directorate, OECD, 2 rue André Pascal, 75775 Paris Cedex 16, France.

The release of this working paper has been authorised by Martine Durand, OECD Chief Statistician and Director of the OECD Statistics Directorate.

This document and any map included herein are without prejudice to the status of or sovereignty over any territory, to the delimitation of international frontiers and boundaries and to the name of any territory, city or area.

\section{http://www.oecd.org/std/publicationsdocuments/workingpapers/}




\begin{abstract}
This paper applies the Inclusive Growth framework to the OECD Regional Well-being Database in order to compute multidimensional living standards (MDLS) among OECD regions from the early 2000s to 2012. MDLS are based on the equivalent income approach, where, for different income groups, the monetised value of health status and unemployment are added to disposable income and aggregated with a generalised mean function to allow inequality to be taken into account. Results highlight that, due to the spatial concentration of good and bad outcomes, regional disparities are amplified when observed through the lens of MDLS as opposed to income-based regional disparities. The paper also shows that people living in metropolitan regions experienced, on average, higher levels of MDLS but also a sharper decline during the economic crisis. Growth of MDLS in metropolitan regions during this period was characterised by a higher contribution of life expectancy and a lower contribution of income inequality with respect to the other regions.
\end{abstract}

\title{
RÉSUMÉ
}

Nous avons appliqué ici le cadre de l'OCDE pour une croissance inclusive à la base de données statistiques sur le bien-être régional afin d'obtenir une mesure multidimensionnelle du niveau de vie dans les différentes régions de la zone OCDE pour la période allant du début des années 2000 à 2012. Le niveau de vie multidimensionnel est calculé sur la base d'un revenu équivalent lui-même obtenu, pour différentes catégories de revenu, par l'ajout au revenu disponible d'une valeur monétisée de l'état de santé et de l'emploi agrégée selon la formule de la moyenne généralisée. Les résultats montrent que, du fait de la concentration géographique des meilleures performances, les disparités régionales sont amplifiées lorsqu'on les observe à travers le prisme du niveau de vie multidimensionnel et non plus sur la base du revenu monétaire. On note en outre que le niveau de vie multidimensionnel est en moyenne plus élevé dans les grandes régions métropolitaines, mais que ces régions métropolitaines ont aussi accusé une baisse relativement plus forte qu'ailleurs pendant la crise économique. Par rapport aux autres régions, l'espérance de vie a eu une incidence plus importante et les inégalités de revenu une incidence moins importante sur la progression des niveaux de vie multidimensionnels dans les grandes métropoles. 


\section{ACKNOWLEDGEMENTS}

This paper is the result of a collaboration between the Directorate for Public Governance and Territorial Development and the Statistics Directorate of the OECD. The authors wish to acknowledge the financial support by the Ford Foundation towards the work "Making inclusive growth happen in cities and regions" and the comments and suggestions provided by several OECD colleagues (Romina Boarini, Monica Brezzi, Luiz De Mello, Marco Mira D'Ercole and Joaquim Oliveira Martins), Delegates to the OECD Working Party on Territorial Indicators and participants to a seminar where a first version of this paper was presented. 


\section{TABLE OF CONTENTS}

WHERE IS INCLUSIVE GROWTH HAPPENING? MAPPING MULTI-DIMENSIONAL LIVING

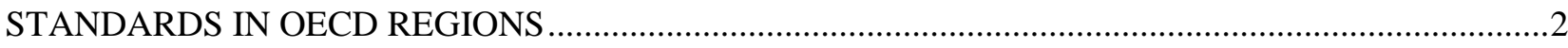

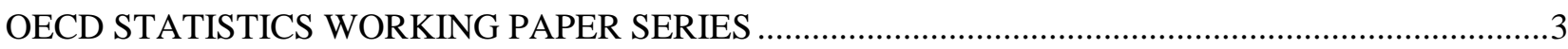

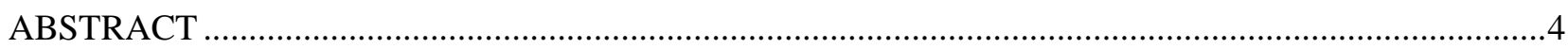

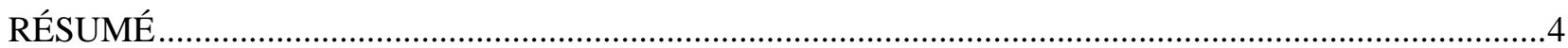

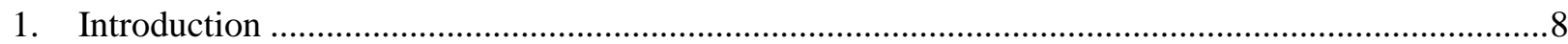

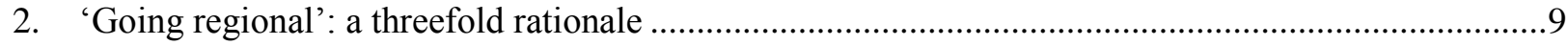

3. Inclusive Growth and Multi-Dimensional Living Standards .......................................................10

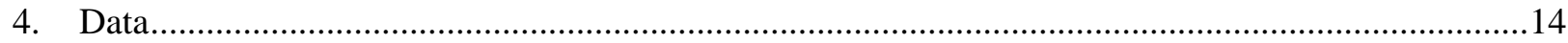

5. Mapping Multi-Dimensional Living Standards across OECD regions ….......................................17

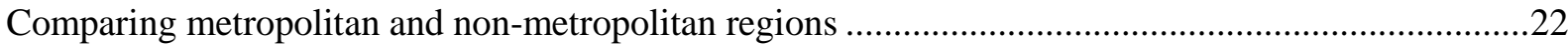

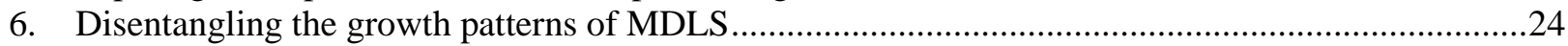

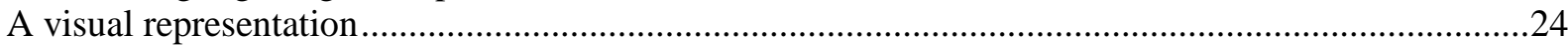

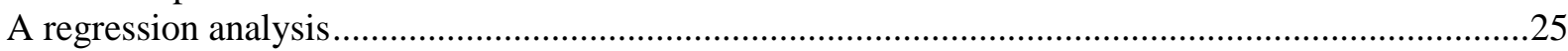

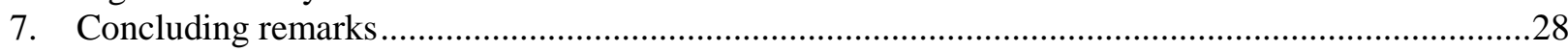

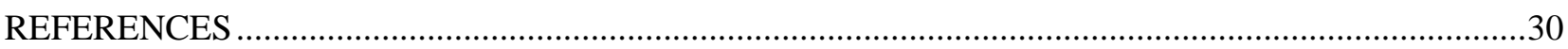

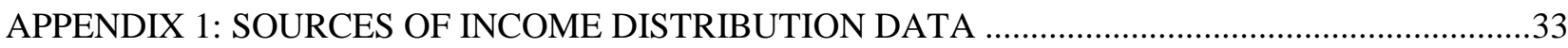

APPENDIX 2: CALIBRATION OF THE AVERSION TO INEQUALITY PARAMETER FOR THE

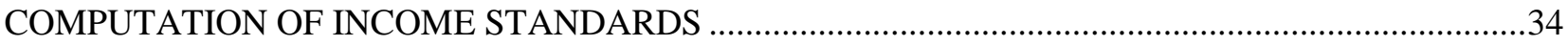

APPENDIX 3. MDLS GROWTH IN OECD REGIONS: CONTRIBUTION BY DIMENSIONS ..............36

\section{Tables}

Table 1. Groups of regions by patterns of inclusive growth (2003-2011) and their characteristics ....25

Table 2. List of independent variables used in regression analysis ..................................................27

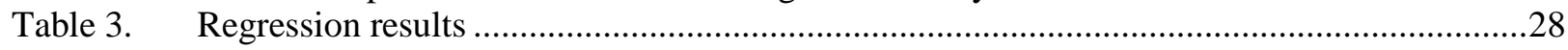

Table A.1. Data sources for income distribution at regional level.......................................................33

Table A.2. Mean aversion to inequality parameter according to the targeted income group, by country......

\section{Figures}

Figure 1. A map of multidimensional living standards, OECD TL2 regions ...................................17

Figure 2. Regional disparities in MDLS and in household disposable income, 2012 .......................18

Figure 3. Differences in the growth of MDLS and contribution of each underlying component between the fastest and slowest growing regions, 2003-2012. 
Figure 4. Growth in GDP per capita and multidimensional living standards in OECD regions, 2003-12 .20

Figure 5. Changes in multidimensional living standards in each country's top performing regions and relative contributions of its components, pre- and post-economic crisis. .21

Figure 6. Relative contributions to changes in multidimensional living standards, fastest growing region by country, around 2003-12

Figure 7. Differences in MDLS and its components between metropolitan and non-metropolitan

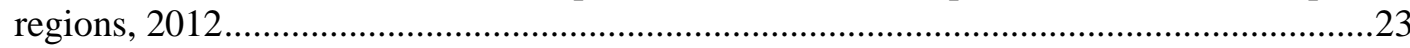

Figure 8. Changes in MDLS and its dimensions in metropolitan and non-metropolitan regions, pre-

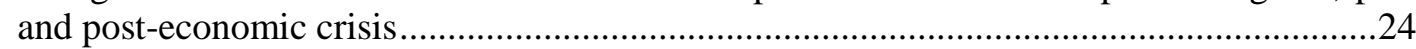

Figure 9. Different patterns of inclusive growth in OECD regions, 2003-2012 _............................25

Figure A.1. Distribution of the aversion to inequality parameter according to the targeted income

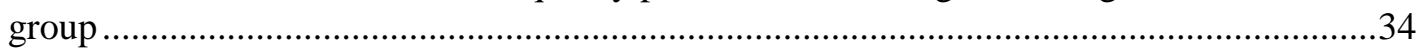

Figure A.2. Relative contribution of household income, longevity, unemployment and income inequality to changes in multidimensional living standards, around 2003-2012 .................36

\section{Boxes}

Box 1. Theoretical approaches for defining well-being and living standards..................................11

Box 2. Methodology to compute multidimensional living standards in OECD regions....................13

Box 3. The OECD Regional Well-being Database and its indicators...............................................16 


\section{Introduction}

1. The recent policy debate has increasingly focused on the need to foster economic growth in a way that translates into higher well-being of people. Strengthening this link is a major challenge for policy makers and it requires new data and new analytical tools to measure and assess the outcomes that matter the most for people, together with their distribution across groups and their interactions. On the data front, the recent OECD work on well-being allows international comparisons to be made either between countries (OECD, 2011) or sub-national regions (OECD, 2014) on a number of dimensions that shape people's material conditions and quality of life. Regarding the evaluation framework, the OECD Inclusive Growth (IG) initiative provides a new way for assessing how economic growth translates into better outcomes and on how these improvements are shared across different groups of people. This framework, which has been applied so far to OECD countries, provides a summary measure of welfare - expressed in monetary terms and called multidimensional living standards (henceforth MDLS) - that accounts for selected dimensions of well-being (income, jobs and health) and includes distributional considerations. The framework builds upon previous OECD work on well-being (OECD, 2011a; 2014a), income inequality (OECD, 2011b; 2015a) and economic growth (OECD, 2015b).

2. This paper assesses MDLS and their subnational trends in the regions of 15 OECD countries where income distribution within regions is observed over time. Regional MDLS are computed by adding the disposable income for different households groups (i.e. income quintiles) in different regions to the monetised values of health and jobs outcomes, which are converted into monetary units through the estimation of shadow prices that are based on people's preferences. The resulting equivalent income of each household group is subsequently aggregated at the level of each region using a generalised mean (Atkinson, 1970) in order to allow inequality to have a negative impact on MDLS. ${ }^{1}$ For reasons of data availability, the indicator of regional MDLS was computed for 209 OECD regions, and covers approximately the period between 2003 and 2012. It has to be acknowledged that the assessment of MDLS required making several hypotheses that might have affected the accuracy of such an assessment. First, a single set of shadow prices were applied to all OECD regions, implying that preferences do not change across space. Second, three dimensions of well-being (income, jobs and health outcomes) do not cover necessarily all aspects of living standards that are important for people. Similarly, the indicators chosen to account for the dimensions considered are far from being perfect. For example, unemployment rate does not catch the aspects related to job quality, which are very important, especially in advanced economies, to measure living standards. All these choices were made for the sake of international comparability and data availability. In this respect, possible extensions of MDSL should include more dimensions (i.e. environment, safety, etc.) and/or improve the indicators chosen to catch the dimensions considered.

3. The measurement of MDLS and its underlying components (i.e. income, jobs, health and income inequality) makes it possible to highlight stark differences in how prosperity translates into better living conditions in the different regions of the same country. Such measures can help in the identification of the places and domains where improvements are most needed, to monitor the spatial concentration of outcomes and improve policy coherence. This is particularly true at sub-national level, where various dimensions of well-being reinforce - or compensate - one another. The complementarities and trade-offs among different strands of policy are in fact most easily identifiable - and most readily manageable where they occur (OECD, 2011b).

$1 \quad$ For illustrative purposes, the results shown by the OECD at national level are obtained by aggregating the equivalent income of different groups of population in ways that give more weight to households in the first and fifth (median) decile of income in each country (OECD, 2014a). 
4. The main results from the analysis are:

- There is a large variation in both levels and growth of living standards across OECD regions. In several countries regions showing improvements co-exist with others where MDLS declined during the last decade.

- Regional disparities in MDLS are consistently starker than those in household disposable income only, reflecting that the different well-being dimensions considered in the framework amplify the concentration of material prosperity in space.

- Growth of GDP per capita does not always translate into higher MDLS, though the two indicators are positively correlated. The correlation between the growth of GDP per capita and that of MDLS in OECD regions is in line with that observed at national level (0.43).

- Metropolitan regions record on average higher levels of MDLS than other regions, although they also display higher levels of income inequalities. However, the effect of the economic crisis in terms of stagnation of MDLS and its underlying dimensions - with the exception of health outcomes - was particularly strong in these areas with respect to the rest of the regions.

- In about half of the regions performing at the top of the MDLS scale, gains in living standards have been faster for people at the bottom part of the income distribution.

- Regional disparities in the growth of MDLS, as measured by the gap between the top and the bottom performing regions, were primarily driven by different trends in income and jobs, while health outcomes played a minor role, as its growth has been spread more equally.

- Preliminary analysis to disentangle the regional patterns of MDLS growth highlights that access to broadband connection was associated with faster growth of income, while higher civic engagement - as measured by voter turnout - was associated to better health outcomes. MDLS growth in metropolitan regions was characterised by a higher contribution of life expectancy and a lower contribution of income inequality with respect to the other regions in the period between 2003 and 2012.

\section{2. 'Going regional': a threefold rationale}

5. There are three main reasons for looking at inclusive growth from a regional (sub-national) perspective.

6. First, people's well-being depends not only on their individual characteristics, but also on those of the place where they live. There is increasing evidence that local conditions affect people's current life satisfaction as well as their long-term outcomes. Using longitudinal data for individuals in US cities, Rothwell and Massey (2015) show that the characteristics of the neighbourhood where individuals live during their childhood, such as average income and the presence of high-quality schools, strongly affect their future earnings. Similarly, Chetty, Hendren, Kline, and Saez (2014) show that intergenerational income mobility is very heterogeneous across space in the US, being significantly higher in counties with lower residential segregation, lower income inequality and better schools. The empirical literature provides evidence of several other place characteristics that can significantly affect well-being of individuals and communities. For example, life satisfaction was found to be associated with the presence of green areas for urban citizens (Ambrey and Fleming, 2013; White et al., 2013), better climate (Ferreira and Moro, 2010; Rehdanz and Maddison, 2005), lower crime (Frey et al., 2009) and smaller city size (Morrison, 2011). 
7. A second argument supporting the relevance of a subnational perspective is that there is a considerable regional variation in the distribution of socio-economic conditions and people's well-being within countries (OECD, 2014; 2015). Differences in well-being between regions in the same country are often higher than differences between countries, making national averages sometimes misleading. For example, regional differences in the employment rate in Italy in 2013 ranged from $40 \%$ in Campania to $73 \%$ in the region of Bolzano, which is similar to the range observed at national level across all OECD countries. Health outcomes, as measured by life expectancy, also show important differences across regions. In the United States, for example, the difference in life expectancy between the states with the highest and the lowest value of such indicator is six years, which is not much lower than the 8-year gap observed across all OECD countries. Despite a general increase in health outcomes in most developed countries, recent evidence also shows that spatial disparities in health outcomes did not decrease in the last two decades (Maynou, 2015). Other well-being dimensions are intrinsically related with local characteristics, including the type of geography. For example, access to services is generally higher in urban than rural areas, while air quality varies dramatically across space and is particularly low in cities and other places of high concentration of economic activities.

8. A third argument to apply the concept of inclusive growth at regional level relates to the policymaking process. Sub-national governments have a stake in policies that promote inclusive growth. In most OECD countries, sub-national levels of government contribute in important ways to both the design and implementation of a range of policies impacting directly on people's lives. Across the OECD, sub-national governments carry out around $40 \%$ of total public spending in the OECD. Training programs for developing skills (jobs), health care (in some countries almost completely decentralised), crime, housing and land-use are among the domains where sub-national and regional governments play a dominant role. National policies might also have different effects across space, depending on the characteristics of the region, including the quality of governance and the capacity of governments to effectively co-ordinate across the different levels of government (OECD, 2014d). In addition, many of the interactions among policies are location-specific. For example, policies on land-use, transport and housing are designed and implemented differently in cities and rural areas. An assessment of living standards at regional level can thus help identify the policy challenges and the trade-offs faced by both national and sub-national policy makers.

\section{Inclusive Growth and Multi-Dimensional Living Standards}

9. Inclusive Growth means that economic growth creates opportunities for all groups of people and translates to better lives in terms of both material conditions and quality of life. The need to assess the extent to which economic growth translates into higher well-being for people requires a measure of living standards that takes into account several well-being dimensions. The OECD Inclusive Growth framework (OECD, 2014a) adopts a specific approach to measure the improvements of (policy actionable) outcomes that matter most to people's lives and of the extent to which such improvements are shared across groups of people. The measurement framework is based on the computation of a welfare measure called MultiDimensional Living Standards (MDLS), which is based on the equivalent income approach (Box 1). 


\section{Box 1. Theoretical approaches for defining well-being and living standards}

Welfare economics encompasses different approaches to define and measure well-being. The most important ones are the capabilities approach, the subjective well-being approach, and the equivalent income approach (for a review, see Fleurbaey and Blanchet (2013)). These three approaches do not differ only in terms of how the concept of well-being is measured, but also in the normative assumptions underlying the concept, in particular in terms of respect of individual preferences and the scope of individual responsibility.

The capabilities approach has its origins in the work of Amartya Sen and defines welfare as a function of the set of achievements (functionings), i.e. what one manages to do or to be in various life domains as well as of the freedom they have in choosing among these achievements (capabilities). For instance consider the case of two undernourished people, one of whom has deliberately decided to fast for religious belief, while the other is constrained by a lack of resources. While a welfarist approach would make no difference in evaluating the well-being of these two people, the capabilities approach would assess that the welfare of the second person is lower than that of the first. In sum, the notion of capabilities makes it possible to consider the real opportunities of an individual to achieve his/her functionings. Underlying this vision is the fact of considering individuals as fully responsible for their choices, which is somewhat strong (as implicitly assuming that preferences, such as religious ones, are always "chosen" by individuals). In this perspective, Sen (1999) conceives development as the historical process of expanding people's choices. One challenge for adopting the capabilities approach is that it is hard to come up with measures of such capabilities.

Welfarism maintains that well-being is about end-states or outcomes only, irrespective of the reasons and causes that have led to people to achieve that particular state. The dominant welfarist approach is the one used by most economists, based on comparisons of income and consumption bundles. The subjective well-being approach may also be seen as an example of welfarism. This approach proxies the traditional notion of utility in economics with overall life satisfaction or happiness, as measured through surveys. One limitation of this approach is that life satisfaction may depend on "needs", which in turn are affected by the social environment to which each person relates. For example, a CEO of a large firm will have different needs than a school professor, and their respective levels of life satisfaction may differ according to how they relate with the people they meet every day. In other words, the satisfaction approach would suggest compensating individuals with high aspirations and expensive tastes, while it could leave uncompensated people with objective poor physical and material conditions.

The equivalent income approach consists in measuring well-being in terms of an income metrics, but including other non-material dimensions, such as, for example, health and jobs outcomes. The nonmaterial dimensions are aggregated with the income one by attributing to each of them a "shadow price", which should reflect individual's own preferences. Shadow prices can be obtained with different methods, for example through life satisfaction regressions (subjective shadow prices) or through calibrated utility functions (model-based shadow prices). Shadow prices allow computing the equivalent income, which is the level of income at which an individual is indifferent between his/her current situation and the one where he/she would attain a reference value for the non-material dimensions. The equivalent income approach respects preferences in the evaluation of individual achievements, since the latter are evaluated on the basis of individuals' own conceptions about what is a good life. In addition, and differently from the previous two approaches, measuring well-being through the equivalent income approach respects the same-preference principle, which implies that the ordering of preference is respected for interpersonal comparisons.

Source: Decancq, K., Fleurbaey, M., Schokkaert, E. (2015), "Inequality, Income, and Well-Being", Handbook of Income Distribution, Volume 2A, Elsevier, pp. 73-140.

10. The index of MDLS considers three well-being dimensions, namely household income, jobs and health. The choice of these dimensions is based on people's preferences, as revealed through empirical micro-analyses on the main determinants of people's life satisfaction (Boarini et al., 2012). The indicators that are used to measure such dimensions are, respectively, household disposable income, the unemployment rate and life expectancy at birth. Each of these indicators is expressed in different units and, 
as such, they are not directly comparable. The computation of MDLS is made possible by adopting an equivalent income or money-metric approach (Murtin et al., 2015), which requires the identification of shadow prices for the non-income dimensions (i.e. jobs and health) in order to convert them into monetary units. Shadow prices are then used to compute the equivalent income of each person, which is the level of income that would make an individual indifferent between his/her current situation and the one where the other non-income dimensions were set at their respective benchmarks (e.g. the maximum life expectancy and a situation without unemployment). The MDLS methodology applies this method to each income group in each region; because of data constraints, the methodology relies on household income data pertaining to various quintiles of the distribution, and on the average unemployment and life expectancy pertaining to each country or region. Subsequently, living standards of each income group are aggregated by region, using a generalised mean (Atkinson, 1970). Such aggregation can give a different importance to each group depending on the "aversion to inequality" chosen in the aggregation. The detailed methodology to compute MDSL is described in Box 2. 


\section{Box 2. Methodology to compute multidimensional living standards in OECD regions}

Identification of shadow prices of well-being dimensions: income, jobs, health

There are several approaches to computing shadow prices. A first approach is based on stated preferences and consists in using specific surveys and adopting a contingent valuation or a choice modelling method. The stated preference approach is usually costly and difficult to implement on an international basis if prices of the non-material dimensions have to be estimated for a large set of countries. A second approach is that of revealed preference, which consists in identifying values for non-market goods (e.g. one additional year of life expectancy) through 'complementary' markets providing the required information. Hedonic price methods are a typical example of a revealed preference approach. For example, the measurement of the economic value of noise can be approximated through housing prices in different areas having similar characteristics but different levels of noise. Houses in noisy areas should be cheaper than comparable houses in quieter areas. A third approach consists in identifying shadow prices through life satisfaction regressions. This is the approach used in the OECD Inclusive Growth framework (Murtin et al., 2015; OECD, 2014a). Based on this approach, the first step consists in running life satisfaction regressions at country level (panel), as follows:

$$
\text { Life_Sat }{ }_{j, t}=a_{j}+b_{t}+\alpha \log y_{j, t}+\beta^{1} L i f e_{-} \operatorname{expt}_{j, t}+\beta^{2} U_{j, t}+\varepsilon,
$$

where $a_{j}, b_{i}, \alpha, \beta_{1}$ and $\beta_{2}$ are coefficients to be estimated. $y_{j, t}$, Life_expt $t_{j, t}$ and $U_{j, t}$ are the disposable household income, the average number of years of life expectancy and the unemployment rate in country $j$ at time $t$, respectively. Regressions are run at country level in order to reduce the influence of measurement errors and unobserved heterogeneity that can affect results of micro-level analyses (Murtin et al., 2015).

From equation [1], the shadow price of an additional year of life expectancy is the (subjective) income necessary to maintain life satisfaction constant. Such shadow price is obtained as follows:

$$
p_{j, i}^{\text {life expt }}=y_{j, i}\left[1-\exp \left(-\frac{\beta^{1}}{\alpha}\right)\right]
$$

Similarly, the shadow price of a decrease of one percentage point of unemployment rate is the subjective income necessary to maintain life satisfaction constant, which is obtained as follows:

$$
p_{j, i}^{U}=y_{j, i}\left[1-\exp \left(-\frac{\beta^{2}}{\alpha}\right)\right]
$$

The identification of shadow price as in equation [1] and [2] is not replicable exactly using regional data. As data on life satisfaction are not available at subnational level for most countries, equation [1] cannot be estimated with regional data directly. As a solution to this limitation, the shadow prices used in this work are those of Murtin et al. (2015), which are based on a panel of OECD countries.

\section{Computing regional equivalent income and multi-dimensional living standards}

Once shadow prices are estimated, it is possible to compute the "equivalent incomes" (or "monetised well-being") of different groups of people within each region. This phase accounts for the distributional aspect of living standards through the measurement of equivalent income by social groups, separately. Social groups are identified, for each region, by taking the quintiles of the distribution of household disposable income. Thus, equivalent income by income quintile is computed by applying the following formula:

2 More specifically, the parameters $\alpha, \beta^{l}$, and $\beta^{2}$ have been estimated to be $3.538,0.192$ and -0.063 , respectively. Consequently, the shadow price of an additional year of life expectancy is $5.3 \%$ of household income, while the shadow price of a decrease of one percentage point in the unemployment rate is $1.8 \%$ of household income. 


$$
Y_{d}^{*}=y_{d}-U^{b *} p^{u}-\Delta \text { Life_expt }{ }^{*} p^{\text {life_expt }},
$$

where $y_{d}$ is the mean of the $d$-th quintile of household disposable income; $p^{u}$ and $p^{\text {life } \_x p t}$ are the shadow prices allowing to convert jobs and health outcomes in monetary terms; $\Delta$ Life_expt is the difference in the number of years of life expectancy between the region with the highest life expectancy and the $i$-th region; $U^{b}$ is the difference between the unemployment rate and the benchmark unemployment rate, which is set to zero.

Finally, multi-dimensional living standards are obtained, for each region, by aggregating the equivalent incomes of each quintile using a social welfare function. Aggregation of individual outcomes has been widely debated in social welfare theory, one issue being that different choices of aggregation reflect different views about inequality. Consistently with the OECD approach to measurement of Inclusive Growth at national level, the function chosen to aggregate the equivalent income for the different quintiles is the Atkinson's general mean (Atkinson, 1970), which is defined as follows:

$$
M D L S_{i}=\left(\frac{1}{5} \sum_{d}^{5} Y_{d, i}^{1-\tau}\right)^{\frac{1}{1-\tau}}
$$

where $M D L S_{i}$ is the multi-dimensional living standards of the $i$-th region, $Y_{d, i}$ is the equivalent income of the $d$-th quintile in the $i$-th region as computed in [4] and $\tau$ is a parameter that reflects the society's aversion to inequality. The way inequality enters in the computation of MDLS depends on the choice of $\tau$. When it is equal to zero, equation [5] coincides with the simple average income, as in a pure welfarist approach. Higher values of $\tau$ reflect a higher aversion to inequality. In this paper, the calculation of regional MDLS was carried out by setting $\tau=1.2$, which implicitly takes the median income as the reference group (i.e. the measure of multidimensional living standards obtained when setting the inequality-aversion parameter at 1.2 are reflective of the median household welfare, see Appendix 2 for details). Other choices on the parameter $\tau$ could be made, to attribute more weight to other segments of the population. On the whole, an increase of MDLS can be driven by an improvement of one or more of the outcomes considered in this framework (i.e. income, health or jobs) but also by reduced inequality.

Source : Adaptation based on OECD (2014b)

\section{Data}

11. The computation of regional MDLS requires in the first place the availability of outcome indicators at regional level on income, health and jobs dimensions. The OECD Regional Well-being Database (Box 3) provides suitable indicators over a time span of about a decade and it is the main data source for the computation of regional MDLS. The indicators used to measure outcomes in the income, jobs and health dimensions are generally consistent with those used in the IG framework at national level. More specifically, health and jobs are measured in terms of life expectancy at birth and unemployment rate, respectively. With respect to the income dimension, the computation of MDLS requires information on both levels and distribution. ${ }^{3}$

3 Data on the distribution of income is necessary in order to compute living standards for the different groups of people (i.e. equation (5) in Box 2). Limited availability of data on the distribution of outcomes at regional level is certainly the major data constraint to deal with for the computation of regional MDLS. At national level, the inclusive growth framework identifies social groups according to income only. The same choice is applied at regional level, where quintiles of disposable household income are used to identify social groups. 
12. Data on both levels and distribution of disposable household income come from OECD computations based on national income surveys. ${ }^{4}$ Some of these indicators are publicly available in the OECD Regional Well-being Database for 28 countries, but they refer to one point in time only. ${ }^{5}$ Given the dynamic nature of the IG concept, it was necessary to expand the availability of these data over time in order to measure changes in MDLS and assess the patterns of IG followed by various OECD regions, at least in the years following the recent economic crisis. To this end, indicators over time of the distribution of household disposable income within Territorial Level 2 (TL2) regions ${ }^{6}$ were estimated for 15 OECD countries through a dedicated household-level data calculation (Royuela, Veneri and Ramos, 2014). The countries considered in the analysis are Belgium, Canada, Chile, the Czech Republic, Estonia, Finland, France, Greece, Italy, Korea, Luxembourg, Mexico, Spain, the United Kingdom, and the United States. Except for a few cases, household income data were estimated for several points in time between 2003 and 2012. Table A1 in Appendix 1 reports the sources of data and the waves of national income surveys that were used for obtaining such indicators. More details on the sources and methods can be found in Royuela, Veneri and Ramos (2014).

13. Regarding the other two outcome indicators, life expectancy at birth is also available for almost all OECD regions. In the case of Chile, Korea and the United States, where life expectancy data are not available every year, the missing points between observations were linearly interpolated in order to maximise the time span considered in the computation of MDLS. Unemployment rates at regional level are instead available for all OECD regions on a yearly basis (Box 3 ).

\footnotetext{
$4 \quad$ A potential alternative data source for levels of disposable income is provided by national accounts (which provide data on household disposable income per capita); for consistency reasons, in this paper data on both the levels and distribution of income are taken from national income survey. National accounts-based data on household income are obtained by adding to the balance of primary income all current transfers from the government, except social transfers in kind, and subtracting current transfers paid by households such as income taxes, regular taxes on wealth, regular inter-household cash transfers and social contributions. Using national accounts data at the regional level would allow covering a large number of countries and a longer time span, often longer than a decade, as well as to improve cross-country comparability (Fesseau and Van de Ven, 2014). However, regional accounts do not provide information on the distribution of income, thus the time span considered in the analysis would be in any case constrained by the availability of regional estimates of quintiles of household disposable income from national income surveys.

5 Details on the estimation methods are provided by Piacentini (2014).

6 TL2 regions are the subnational entities usually corresponding to the first government layer below the national or federal one (see Box 3 for more details).
} 


\section{Box 3. The OECD Regional Well-being Database and its indicators}

The OECD Regional Well-being Database currently covers nine dimensions of well-being. These dimensions are income, jobs, housing, environment, access to services, education, safety, health and civic engagement. For each dimension, the database, which is publicly available, provides at least one indicator. These indicators are currently provided at the TL2 scale, which represents the largest subnational definition recognised by the OECD. TL2 corresponds to administrative regions that represent the largest government tier after the national (or federal) one. For example, TL2 regions correspond to states in Mexico and in the United States, to provinces in Canada, to the nations (England, Scotland, Wales, etc.) in the United Kingdom and to Autonomous communities in Spain. Exceptions are the Netherlands and New Zealand, where TL2 regions do not correspond to administrative regions, but to clusters of them.

All indicators available in the Regional Well-being Database are reported in the table below, together with the number of countries and the years of data availability. Access to service is measured by the share of households having broadband access. This dimension is specific to the OECD regional well-being database, while it is not included in the OECD well-being framework at national level (OECD, 2011). As a pilot exercise the average distance and travel time from the closest hospital has been estimated for 4 countries (France, Italy, the United States, Germany) as an alternative measure of accessibility to services (OECD, 2012). The distance to the hospitals (both in time and kilometres) is computed as a weighted average based on the number of people living in each square kilometre within each region.

The OECD Regional Well-being Database also provides data on income distribution within each TL2 regions. More specifically, both the Gini Index for the distribution of equivalised disposable household income and the average levels of household disposable income by quintile are available in the database for each region at one point in time (around 2011) and for 28 countries.

Main well-being indicators available at regional level (TL2)

\begin{tabular}{|c|c|c|c|}
\hline $\begin{array}{l}\text { Well-being } \\
\text { dimension }\end{array}$ & Indicator & $\begin{array}{l}\text { N. of countries } \\
\text { with data at TL2 }\end{array}$ & $\begin{array}{l}\text { Period } \\
\text { covered }\end{array}$ \\
\hline \multirow{3}{*}{ Income } & $\begin{array}{l}\text { Household disposable income per capita (reg. accounts } \\
\text { data) }\end{array}$ & (2) & 1995-2011 \\
\hline & Household income distribution (several indicators: Gini & & \\
\hline & Index, income by quintile) & 28 & 2011 \\
\hline \multirow{2}{*}{ Jobs } & Employment rate & 34 & $1990-2014$ \\
\hline & Unemployment rate & 34 & $1990-2014$ \\
\hline \multirow{2}{*}{$\begin{array}{l}\text { Housing } \\
\text { Education }\end{array}$} & Number of rooms per person & 32 & 2011 \\
\hline & Share of labour force with at least secondary education & 34 & 2000-2014 \\
\hline \multirow{3}{*}{ Health } & Life expectancy at birth & 33 & $2000-2011$ \\
\hline & Mortality rate & 33 & 2000-2012 \\
\hline & Share of unmet medical needs & 13 & 2011 \\
\hline Environment & Air pollution, level of PM2.5 & 34 & $\begin{array}{r}2002,2005, \\
2008,2011\end{array}$ \\
\hline Safety & Homicide rate & 34 & $1995-2012$ \\
\hline \multirow{2}{*}{$\begin{array}{l}\text { Civic engag. } \\
\text { Access to } \\
\text { services }\end{array}$} & Voter turnout in general election & 34 & $2000-2012$ \\
\hline & Share of households with internet broadband access & 34 & 2007-2013 \\
\hline
\end{tabular}




\section{Mapping Multi-Dimensional Living Standards across OECD regions}

14. Multidimensional living standards are expressed in monetary terms and are a function of household disposable income, life expectancy (health), unemployment rate (jobs), and income inequality. The equivalent income for health and jobs reflects the monetised value of the differences in these outcomes between each region and the region with the benchmark outcome. The latter is set to a zerounemployment ${ }^{7}$ rate for jobs and to the highest life expectancy, which is that in Madrid, Spain (84.2 years). Results for the OECD regions in the 26 countries considered in this paper show that regions in Australia, North and Central Europe and Canada have high MDLS (Figure 1). On the other hand, Southern European and Latin American regions have on average low levels of MDLS.

Figure 1. A map of multidimensional living standards, OECD TL2 regions

Levels around 2012 or latest available year

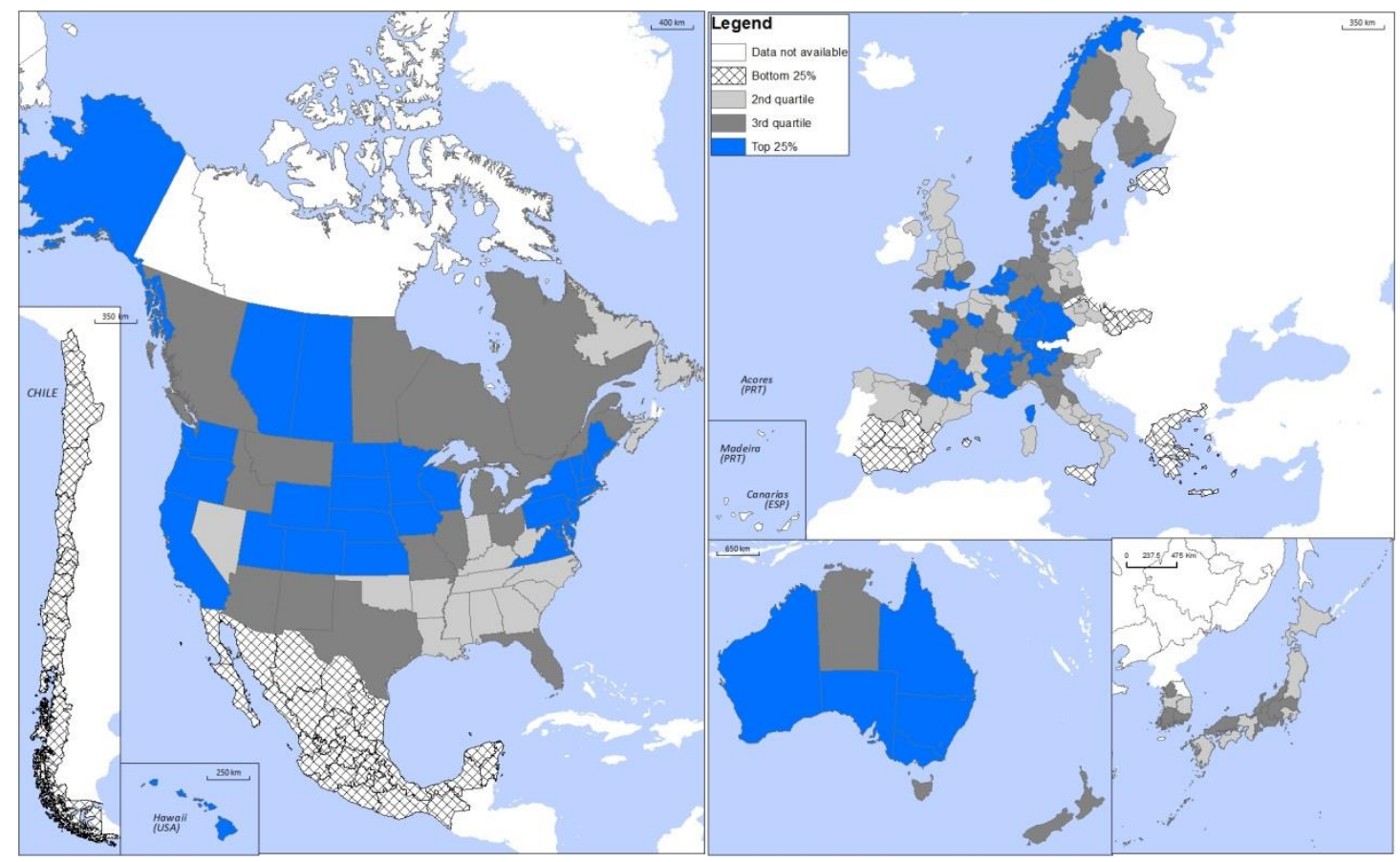

Source: Authors' calculations based on OECD Regional well-being Database and National Income surveys

15. Previous OECD work highlighted large disparities across sub-national regions in OECD countries, in terms of both economic growth and well-being outcomes (OECD, 2013; 2014). Regional disparities are usually assessed by looking at individual outcomes. By looking at MDLS it is possible to highlight the extent to which regional disparities in some specific dimensions are reduced or amplified when considered jointly. While, as shown in Figure 1, common patterns can be observed in the levels of MDLS within countries, two main facts can be highlighted.

7 This choice is consistent with the IG national framework (OECD, 2014b). A possible alternative choice, not envisaged in this work, is to use the non-accelerating inflation rate of unemployment as the benchmark for the jobs dimension or to take the unemployment rate of the region with the lowest recorded value. 
- First, regional disparities - as measured by the coefficient of variation of the MDLS ${ }^{8}$ - have followed different trends over the last decade. Between 2003 and 2012, regional disparities in MDLS have increased in 8 out of the 15 countries considered in this paper (Korea, France, Finland, the United States, Spain and Belgium, Mexico and Chile), while a reduction of disparities was observed in the other countries.

- Second, regional disparities in MDLS are almost always higher than those emerging by looking at disposable income only (Figure 2). This suggests that the various dimensions considered in the IG framework (i.e. jobs, health, income inequality) tend to reinforce the differences observed in terms of household income levels, i.e. people living in regions with high levels of income are also more likely to be employed and to have better health outcomes, on average. Among the 25 countries where regional disparities in MDLS can be assessed, only six countries (Denmark, Greece, Korea, and Switzerland) showed larger disparities in terms of income rather than in terms of MDLS, implying that in these countries regional inequalities in the various well-being outcomes tend to offset each other.

Figure 2. Regional disparities in MDLS and in household disposable income, 2012

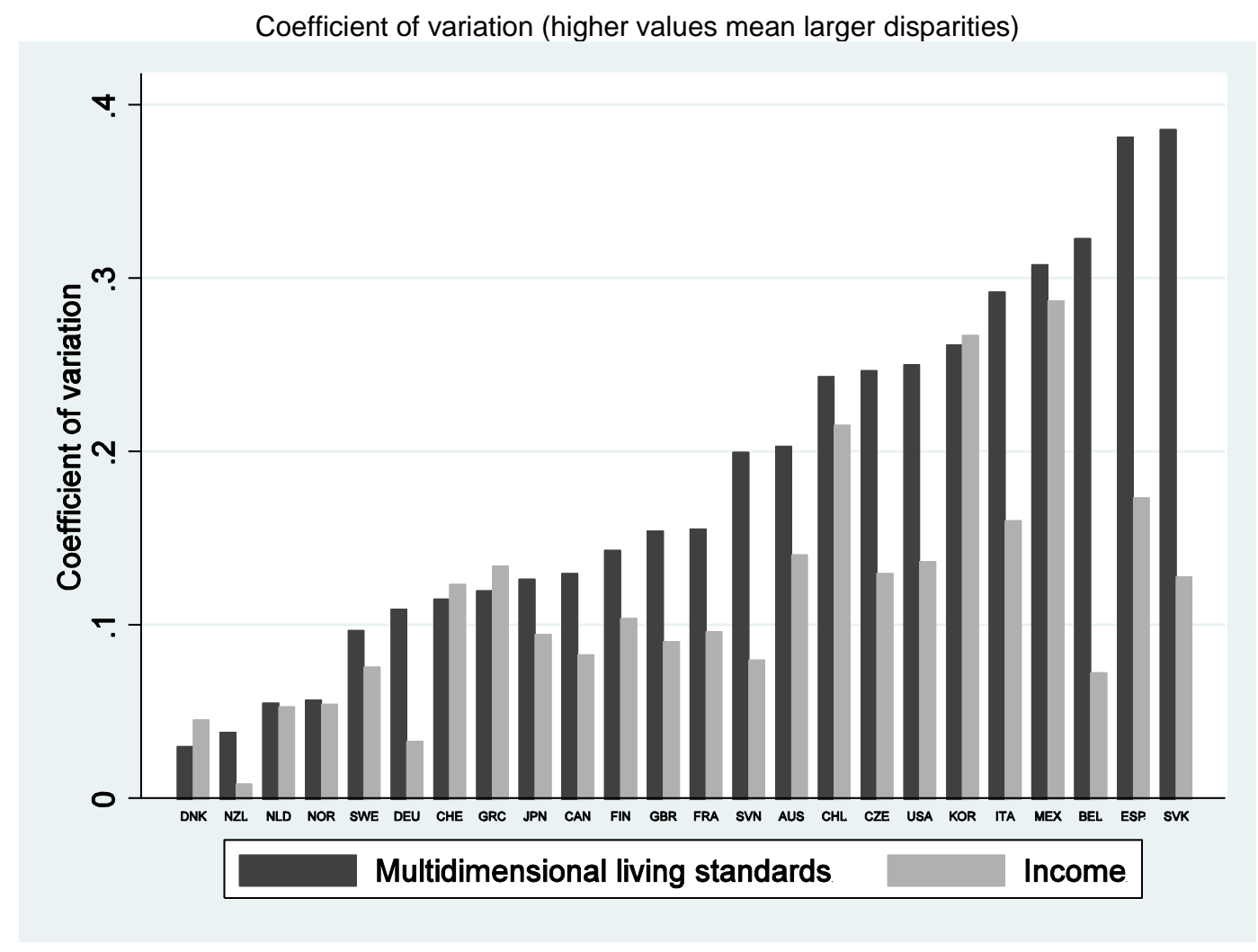

Source: OECD calculations based on OECD Regional Well-being database and national income surveys

16. Large regional disparities can also be observed when looking at the evolution of MDLS. Gaps in the growth rates of MDLS between the top and the bottom performing regions within the same country are

$8 \quad$ The coefficient of variation is the most used indicator in research on measuring regional disparities. It has the advantage of not being too sensitive to the units of measure and the number of regions. It is computed as the ratio between the standard deviation and the mean of each variable. Higher values of the coefficient of variations indicate larger regional disparities. 
particularly high in Mexico, Chile and Spain (Figure 3). In most of the countries considered, the growth of household income was the major driver of differences in MDLS growth between top and bottom performing regions. Changes in unemployment rate and in income inequality also contributed significantly to the observed regional gap in MDLS growth, while the Czech Republic is the only country where income growth reduced such a gap. The contribution of the change in the unemployment rate was particularly high in Greece, France, the Czech Republic, Spain and the United States, while changes in income inequality had an important role in Mexico and Korea. On the other hand, and as expected given the short time span considered, changes in longevity played a minor role in driving regional disparities in living standards.

Figure 3. Differences in the growth of MDLS and contribution of each underlying component between the fastest and slowest growing regions, 2003-2012

Contributions of each component are expressed in equivalent income

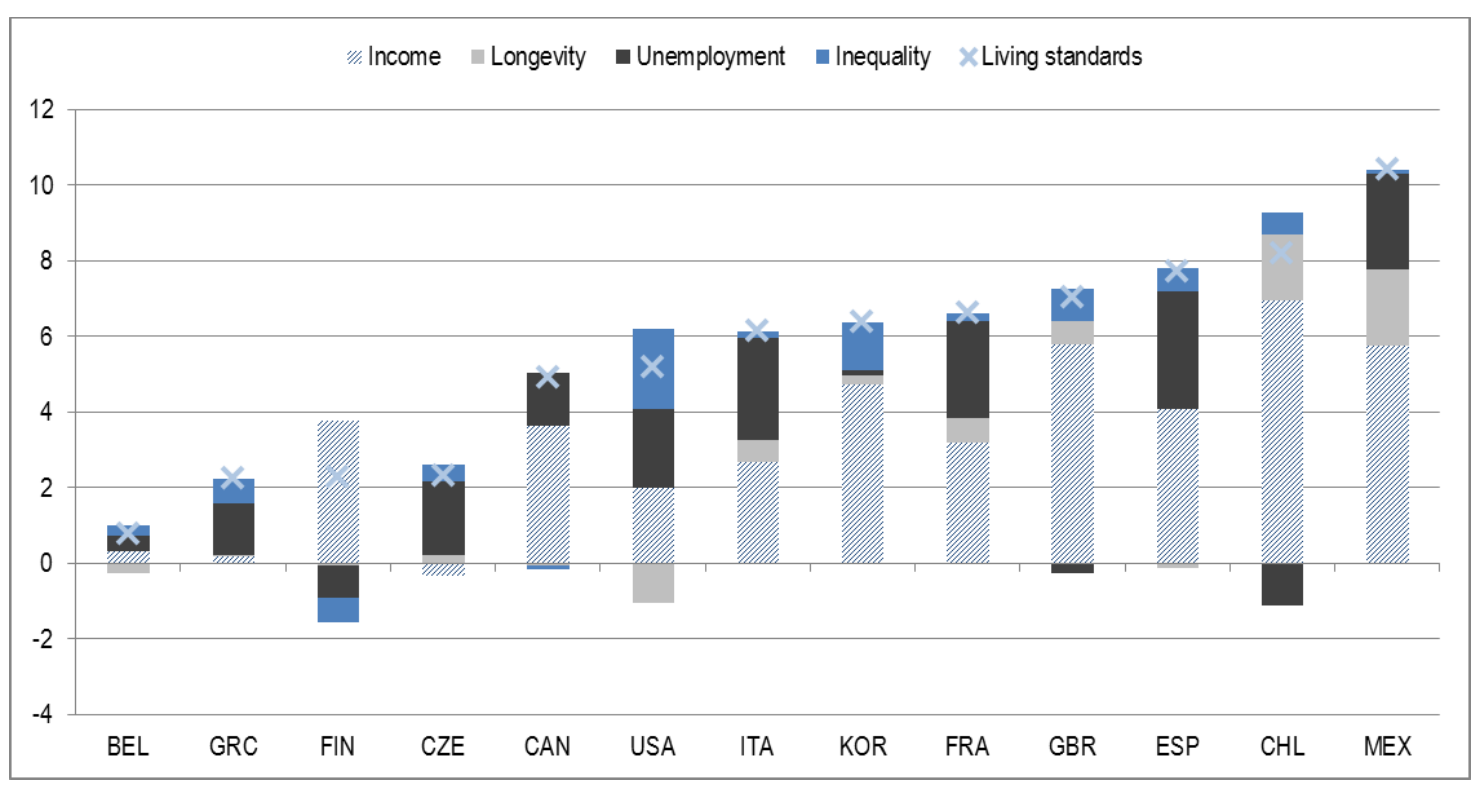

Source: Own elaborations on OECD Regional Well-being Database and national income surveys

17. During the period of analysis ${ }^{9}$, MDLS increased in more than half of all regions, but declined in several others. Changes in MDLS were positively correlated with changes in GDP per capita in OECD regions ${ }^{10}$ (Figure 4) and such a correlation is in line with that found at national level (0.40) (OECD, 2014a). This finding suggests that growth in GDP per capita does not necessarily translate into higher living standards. For example, the region of Helsinki in Finland and the state of Chihuahua in Mexico recorded approximately the same annual growth in GDP per capita (0.66 and 0.69, respectively), but differed significantly in terms of MDLS, showing an improvement and a reduction, respectively. As shown in Figure 4, in most European regions GDP per capita declined between 2003 and 2012; however, most of those regions recorded gains in MDLS, due to improvements in longevity or reduction in inequality. European regions situated below the interpolating line - i.e. those where the growth of MDLS was lower

9 The limited availability of income distribution data at regional level restricts the time-span covered in this analysis. Such period generally ranges between 2003 and 2012, except for Belgium (2003-10), Canada (2004-11), Chile (2003-13), the Czech Republic and Mexico (2004-12), Korea (2004-13), the United Kingdom (2010-13), and the United States (2003-11).

The 0.43 correlation coefficient was obtained using the observations plotted in Figure 3. Outliers were dropped. 
than it could be expected given the growth of GDP per capita - mainly include regions in Spain and Greece, as well as some regions in the United Kingdom (South-East England and Greater London) and Italy (Abruzzo). ${ }^{11}$

Figure 4. Growth in GDP per capita and multidimensional living standards in OECD regions, 2003-12

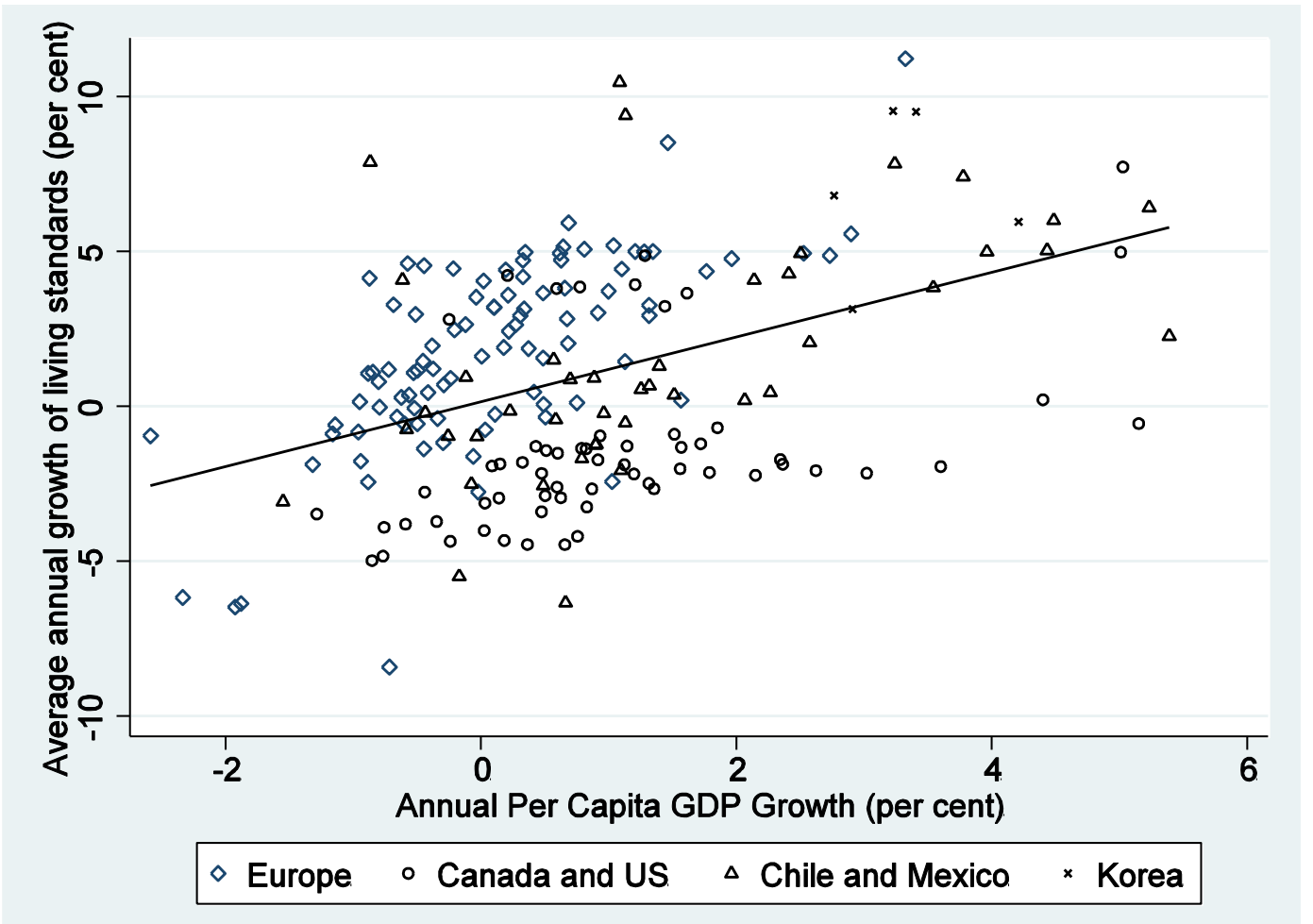

Note: The interpolating line is the linear interpolation that best fits (least squares) the two variables (annual growth rates of GDP per capita and of MDLS, respectively).

Source: Authors' elaborations on OECD Regional Well-being Database and national income surveys

18. Growth in MDLS experienced by regions can vary considerably within the same country. For instance, in France, Italy, Chile, the United States, the United Kingdom and Mexico some regions experienced an overall decrease in MDLS, while others recorded relatively strong increases.

19. The 2008 economic crisis had spatially asymmetric effects on average living standards of different regions. Figure 5 highlights a clear difference between average growth rates of MDLS in the period before and after 2007. Between 2007 and 2012, even the regions that previously experienced the highest growth of MDLS recorded a general stagnation of MDLS and its underlying components. GDP per capita growth followed a similar pattern and the correlation between the growth of MDLS and of GDP per capita was much stronger during the years before 2007 than afterwards. European regions recorded the sharpest falls in MDLS after the start of the crisis, with Greece recording lower MDLS in all regions. In most regions, the lack of improvements in MDLS was driven by stagnant household income and higher unemployment rates. The top performing region in Chile and Korea improved their MDLS, though such improvements were not matched by gains in GDP per capita (Figure 5). With the exception of Canada and France, the top performing regions in each country in the period before 2008 were not anymore top

11 On the whole, growth in GDP per capita was slightly more strongly correlated to the growth of MDLS than with growth of household disposable income (0.43 vs. 0.37$)$. 
performing regions after 2008 , though this change is not necessarily due to the crisis as other factors might be at work.

Figure 5. Changes in multidimensional living standards in each country's top performing regions and relative contributions of its components, pre- and post-economic crisis

a) $2003-2007$

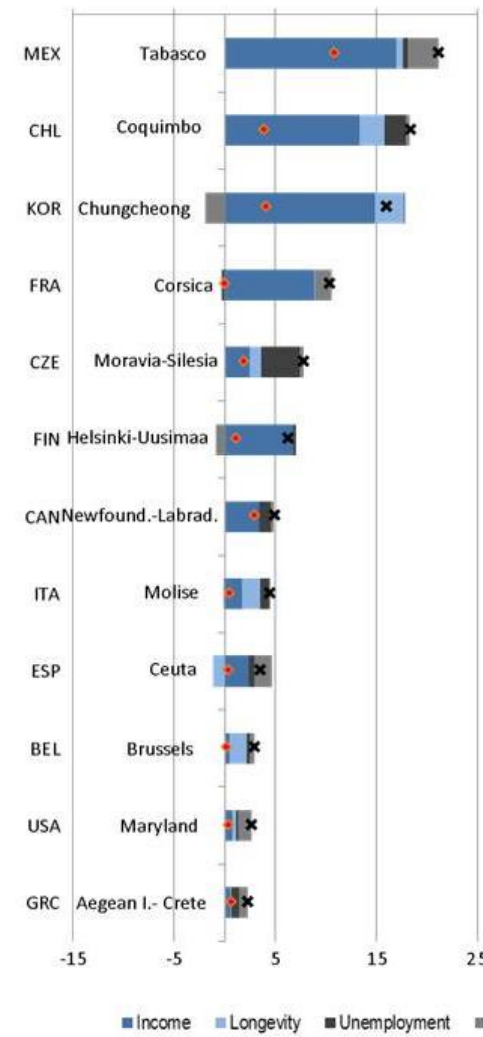

b) $2007-2012$

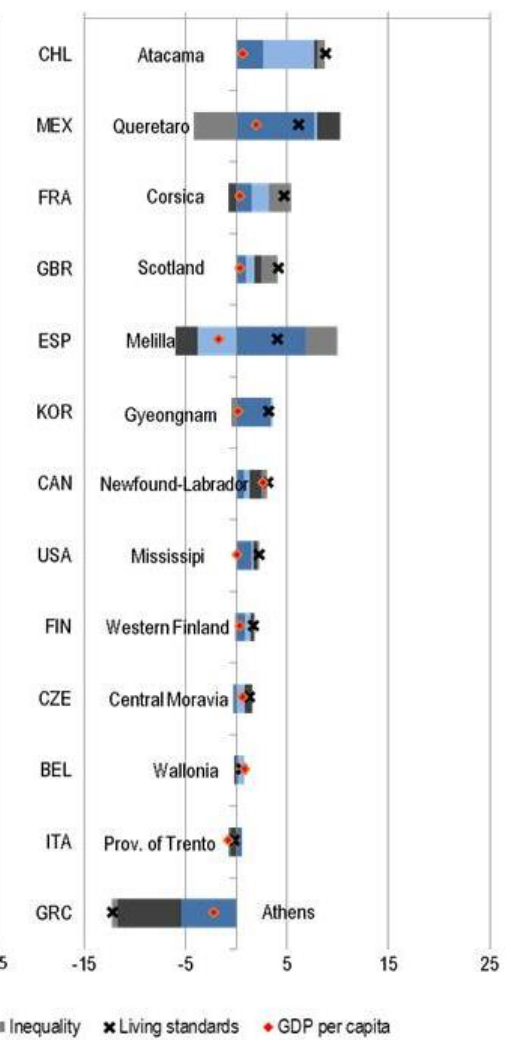

Source: Authors' calculations based on OECD Regional Well-being database and national income surveys

20. The contributions of income, jobs, health and inequality to changes in MDLS are very heterogeneous across regions, even within the same country. Figure 6 shows that, among the regions where MDLS have increased faster, different dimensions have driven this good performance. Higher household income explained most of the improvement in MDLS in the top performing regions in Canada, Chile, France, Estonia and Finland. Higher longevity was the main driving factor in the United Kingdom, Italy and Belgium. In the Moravia-Silesia region in the Czech Republic, on the other hand, the fall in MDLS mainly reflected the higher risk of unemployment. A similar heterogeneity is observed when looking at the regions with the worst performance in terms of changes of MDLS in their respective countries. Generally, lower MDLS in Spanish and Greek regions were mostly driven by lower incomes and higher unemployment rates, but also higher income inequality.

21. MDLS have not necessarily changed at the same pace for all income groups in each region. As indicated in the previous section, the indicator of MDLS used in this paper is computed by aggregating the equivalent income of various quintiles of the population by using an aversion to inequality factor that tends to approximate the conditions of the median households $(\tau=1.2)$. When using a higher aversion to inequality parameter and focusing on the bottom $20 \%$ of the distribution ${ }^{12}$, a slightly higher growth of

12 In order to give more weight to the bottom $20 \%$ of the income distribution, the aversion to inequality parameter was set to 50 . 
living standards can be observed in Estonia and in the top performing region of Belgium, Chile, Italy, Korea and UK, while the opposite was found for Greece, France and Finland (Figure 6). Overall, results on MDLS do not appear too sensitive to changes in the parameter of aversion to inequality.

Figure 6. Relative contributions to changes in multidimensional living standards, fastest growing region by country, around 2003-12

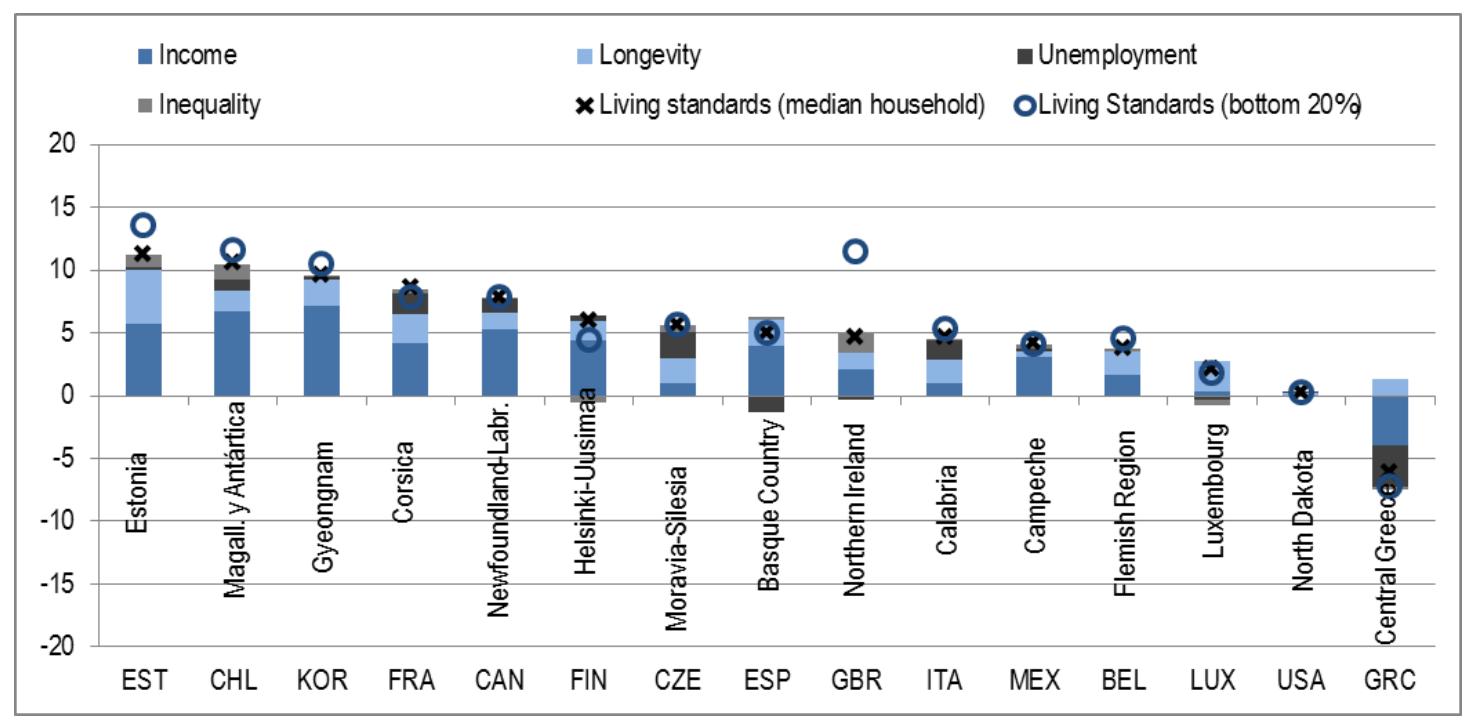

Source: Own elaborations on OECD Regional Well-being database and national income surveys

\section{Comparing metropolitan and non-metropolitan regions}

22. Measuring MDLS at regional level also makes it possible to assess the influence of the degree of urbanisation and size of cities in each region. For the sake of simplicity, regions are classified into two categories, i.e. metropolitan and non-metropolitan regions. Metropolitan regions are those where the highest share of population lives in large cities above 1.5 million people with respect to the share of population living in smaller cities or in non-urban locations. All other regions are considered as nonmetropolitan. In this classification, city boundaries are defined according to the OECD definition of functional urban areas (FUAs) (OECD, 2012b). The use of FUAs allows all cities above 50000 inhabitants to be consistently identified across countries based on their economic definition rather than by using administrative boundaries. FUAs are composed by a high-density urban core and a commuting zone. The former is composed of contiguous grid cells with population density of at least 1500 inhabitants per $\mathrm{km}^{2}$; the latter is composed of those geographical units (i.e. municipalities, wards, counties, etc.) where $15 \%$ or more of their employed residents daily commute to the urban core. ${ }^{13}$

23. MDLS are on average higher in metropolitan regions, where they exceed their non-metropolitan counterparts by around $30 \%$ (Figure 7). ${ }^{14}$ On the other hand, life expectancy and unemployment rate are relatively similar in metropolitan and non-metropolitan regions. The higher average level of household disposable income in metropolitan regions (almost 40\% higher than in other regions) is the most important driver of the differences in MDLS. These results are obtained by pooling all OECD regions, implying that part of these differences is likely to reflect differences among countries. In any case, these differences across regions based on the size of their urban centres are consistent with the evidence that income and

13 For details on the methodology to identify FUAs, please see OECD (2012b).

14 This finding was observed by considering the 15 OECD countries mentioned in the data Section. 
wages tend to increase with city size, mainly because of higher wages paid to urban workers (D'Costa and Overman, 2014). In turn, higher wages reflect higher productivity in cities, driven by factors such as spatial sorting of the most talented workers and most productive firms, and the agglomeration advantages emerging when economic agents are clustered in space (Behrens et al., 2014).

24. As differences in prices of goods and services between urban and rural areas are not considered in this analysis due to a lack of data, income differences across space should be interpreted carefully. ${ }^{15}$ On average, metropolitan regions tend to have better jobs and health, though such differences are not always statistically significant. Income inequality is also higher in metropolitan regions (Royuela et al., 2014). This may reflect the fact that large cities typically attract poor people who migrate to find a job, which can increase income inequality by reducing income at the bottom of the distribution. However, differences in the bottom quintile of the income between metropolitan and non-metropolitan regions are not statistically significant in the sample considered in this work.

Figure 7. Differences in MDLS and its components between metropolitan and non-metropolitan regions, 2012

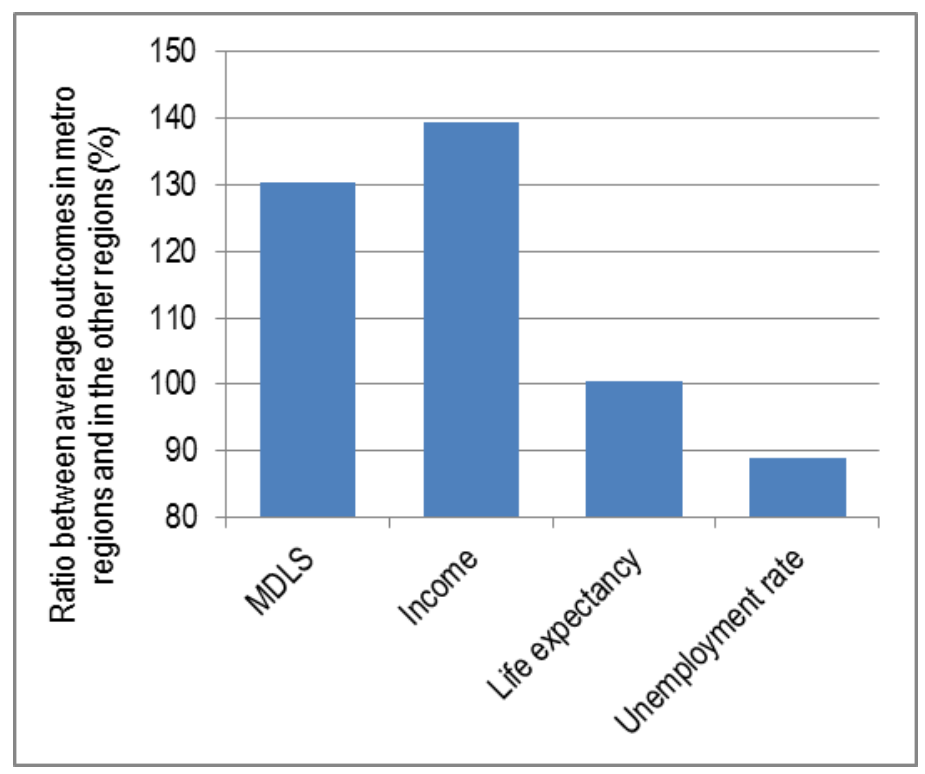

Source: Authors' calculations based on OECD Regional Database

25. During the period 2003-2012, MDLS barely changed in metropolitan regions, while it increased by around $1.3 \%$ per year in non-metropolitan regions. A similar pattern is observed for income, which increased less in metropolitan regions than elsewhere. Income inequalities also increased less in metropolitan regions, though from significantly higher levels. On the other hand, the contribution of health and jobs to the growth of MDLS was not significantly different between the two types of regions.

26. A clearer picture of the different performance of metropolitan and non-metropolitan regions emerges when looking at changes in MDLS in the two sub-periods before and after the economic crisis (Figure 8). Before the crisis, non-metropolitan regions recorded a significantly higher growth of income and of MDLS as well as a higher reduction in unemployment and income inequality, suggesting a process of convergence taking place in that period. After 2007 MDLS and jobs outcomes deteriorated in metropolitan regions at a faster pace than elsewhere.

15 Large spatial differences in prices can dramatically affect the real income available to urban and rural people, as shown in studies of regional poverty rates (Jolliffe, 2006; World Bank, 2015). 
Figure 8. Changes in MDLS and its dimensions in metropolitan and non-metropolitan regions, pre- and posteconomic crisis

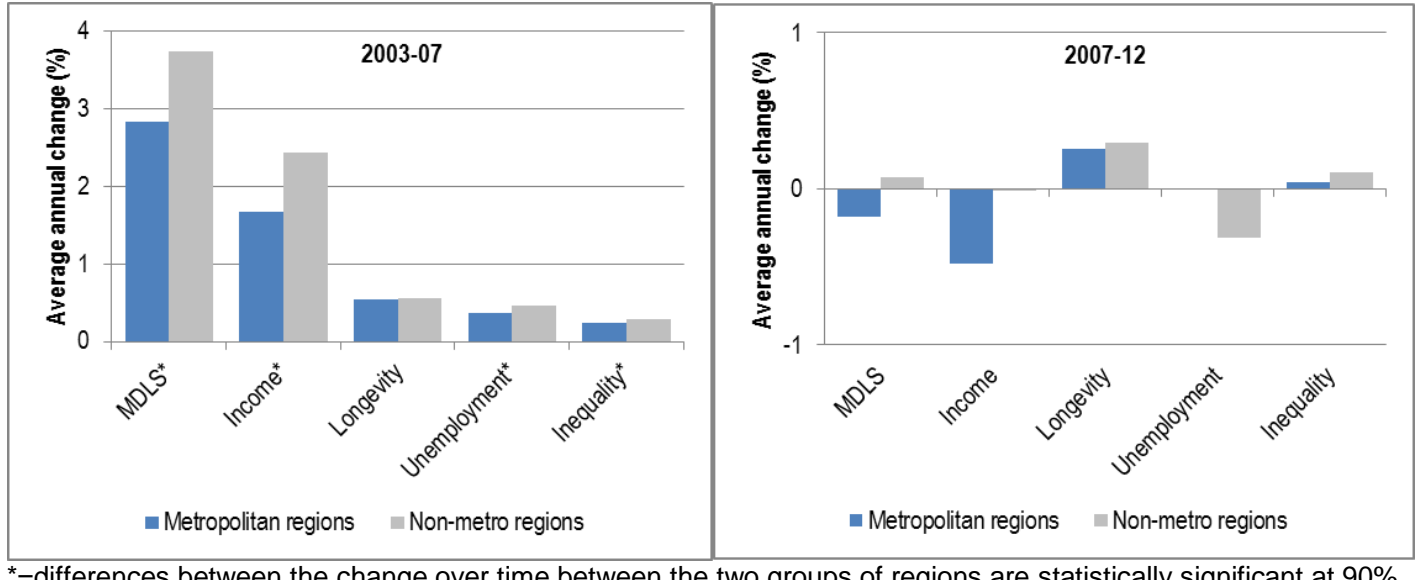

${ }^{*}=$ differences between the change over time between the two groups of regions are statistically significant at $90 \%$ Source: Authors' calculations based on OECD regional database

\section{Disentangling the growth patterns of MDLS}

\section{A visual representation}

27. To better understand the spatially heterogeneous patterns of change in living standards, one can distinguish, first, between regions that experienced an overall increase in MDLS and those that experienced a reduction; and, second, regions where the contribution of income inequality to the change of MDLS increased and those where it fell. This allows identifying four groups of regions: (1) those where MDLS are growing and income inequality declining; (2) those where MDLS are growing due to improvements in income, jobs and health, while the contribution of income inequality is negative; (3) those where the MDLS are falling due to declines in income, jobs and health that are overall larger than the decline in inequality; (4) those where MDLS are falling due to declines in all components (i.e. overall lower income, jobs and health and higher income inequality).

28. Figure 9 maps the different patterns of IG followed by OECD regions in the fifteen countries considered in this paper. Overall, more than half of the regions improved their living standards during the last decade. Most of the regions in Canada, Chile, Belgium, the Czech Republic, Finland and Korea showed positive changes in MDLS together with a reduction in income inequality (group 1). On the other hand, most regions in Southern European countries, as well as in Mexico and the United States displayed a small decline in MDLS accompanied by an increase in income inequality (group 4). Most of the regions in France and several ones in Italy, Finland, Spain, Chile and the United Kingdom displayed an increase of MDLS accompanied by increasing income inequality. Finally, income inequality declined in several regions in the United States and Mexico, but such decline was not accompanied by an overall growth of MDLS. 
Figure 9. Different patterns of inclusive growth in OECD regions, 2003-2012

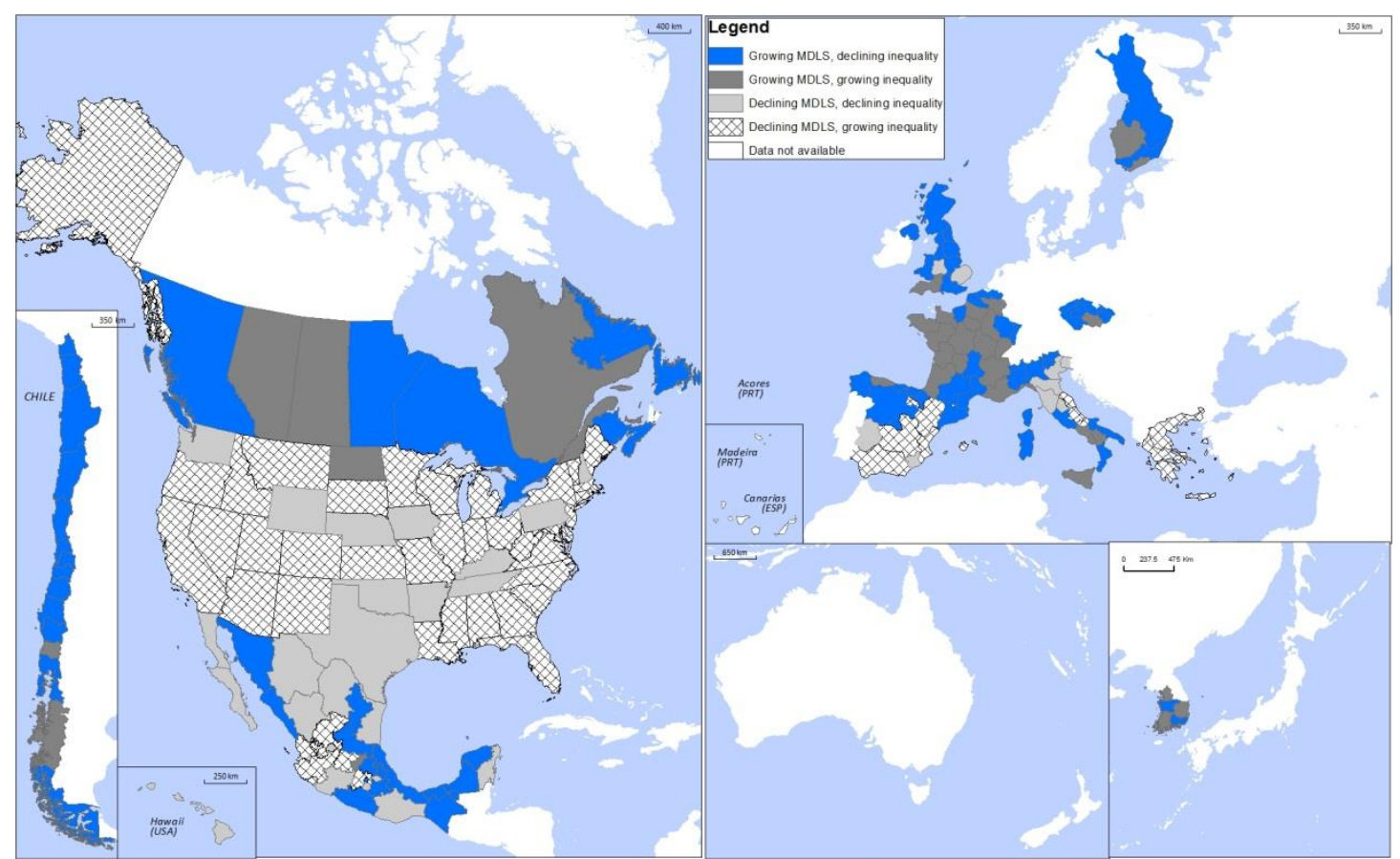

Note: The period covered in the analysis is generally included between 2003 and 2012, except for Belgium (2003-10), Canada (2004-11), Chile (2003-13), the Czech Republic and Mexico (2004-12), Korea (2004-13), the United Kingdom (2010-13), and the United States (2003-11).

Source: OECD elaborations on OECD Regional database and national income surveys

29. Regions where income inequality increased the most were those with the highest levels of income and GDP per capita, but also with the highest unemployment rate, on average (Table 1). In some cases, such as for most Chilean regions, improvement in living standards implied a convergence, since the average MDLS in most of the Chilean regions at the beginning of the period were in the bottom quartile of the OECD regions considered here. On the other hand, regions showing an improvement in MDLS had on average the highest health outcomes and highest access to services, though the urban structure was characterised by relatively smaller city-size with respect to the other group of regions.

Table 1. Groups of regions by patterns of inclusive growth (2003-2012) and their characteristics

\begin{tabular}{lcccccccc}
\hline & \multicolumn{1}{c}{ Unemployment } & Life & GDP per & Access to $\%$ of population \\
& MDLS & Income & rate & expectancy & capita & services & in metro areas \\
\hline Growing MDLS, lower inequality & + & + & + & +++ & + & +++ & + \\
Growing MDLS, growing inequality & ++++ & +++ & ++ & ++++ & +++ & ++++ & ++ \\
Decreasing MDLS, lower inequality & ++ & ++ & +++ & + & ++ & ++ & +++ \\
Decreasing MDLS, growing inequality & +++ & ++++ & ++++ & ++ & ++++ & + & & ++++ \\
\hline
\end{tabular}

The number of "+" in the table indicates the rank across the four groups in terms of the average value of each variable in levels: "++++" indicates the highest average.

Source: OECD calculations based on OECD Regional Database

\section{A regression analysis}

30. A regression analysis can be used to describe how the interplay of regions' characteristics and policies designed and implemented at the sub-national level is associated with the changes in the various components of MDLS. In this section a regression analysis is proposed as a way to illustrate that MDLS 
can be used to better understand how different regional characteristics and policy variables are associated to overall living standards through the link with the different components of the latter. The analysis consists of estimating four equations, one for each component of MDLS growth. Given data constraints and the short time span of the analysis, the baseline specification is a cross-section of about 200 OECD regions. The analysis provides a first description of the factors that might be related to higher growth in MDLS across regions, and should be in no case be read as a causal analysis.

31. In practice, the contribution to changes in MDLS of its four components (income, health, jobs, equality) are regressed on a set of socio-economic characteristics of regions at the beginning of the period $\left(X_{t 0}\right)$, a dummy indicating whether the region is a metropolitan one, and a small set of variables that are actionable by policy $\left(Z_{t 0}\right)$, such as the share of households having broadband access, the density of highways and the number of medical doctors per 1000 inhabitants. The four equations are shown below:

$$
\begin{aligned}
& \Delta y_{t 1-t 0}=\propto_{0}+\propto_{1} y_{t 0}+\propto_{2} X_{t 0}+\propto_{3} \text { metro }_{t 0}+\propto_{4} Z_{t 0}+\varepsilon \\
& \Delta T_{t 1-t 0}=\beta_{0}+\beta_{1} T_{t 0}+\beta_{2} X_{t 0}+\beta_{3} \text { metro }_{t 0}+\beta_{4} Z_{t 0}+u \\
& \Delta U_{t 1-t 0}=\gamma_{0}+\gamma_{1} U_{t 0}+\gamma_{2} X_{t 0}+\gamma_{3} \text { metro }_{t 0}+\gamma_{4} Z_{t 0}+\xi \\
& \Delta I_{t 1-t 0}=\theta_{0}+\theta_{1} I_{t 0}+\theta_{2} X_{t 0}+\theta_{3} \text { metro }_{t 0}+\theta_{4} Z_{t 0}+\omega,
\end{aligned}
$$

where the dependent variables $y, T, U$ and $I$ are the contributions to the changes of MDLS - between $t_{0}$ (around 2003) and $t_{1}$ (around 2012) - of, respectively, disposable household income, life expectancy, unemployment rate, and income inequality. ${ }^{16}$ The sum of the four dependent variables yields the overall change in MDLS. All equations include the initial value of each dependent variable in order to control for convergence. Equations also include a dummy variable on the spatial structure of regions (metro), which is 1 when the share of the regional population living in cities with at least 1.5 million people is the highest. A common set of socio-economic variables was also included in the equations, while the policy variables changed according to the dependent variable considered. The list of variables is reported in Table 2.

32. The socio-economic variables include demographic and labour market controls, i.e. the elderly dependency rate and the share of the labour force with tertiary education, a crucial factor affecting income (Causa et al., 2014), health (Cutler and Muney, 2008; OECD, 2006) and jobs outcomes (Bassanini and Duval, 2006; Mincer, 1993). The share of employment in the industrial sector (industry) controls for the productive structure of the region and its terms of trade, for which a direct measure is not available at regional level. Labour market conditions are measured by the difference between the participation rate of the total population and that for women (with a higher gap expected to show a negative association with the components of MDLS). The equation on the MDLS contribution of health also includes a control for civic engagement (as measured by voter turnout), as a proxy of social capital, a factor which can vary substantially across regions and contribute to people's health (Eriksson, 2011; OECD, 2010).

It is worth highlighting that such variables measure the extent to which the change in the different outcomes contributed to the overall growth of MDLS, while they do not correspond to the simple change over time of the respective outcomes. For example, $\Delta U_{t 1-t 0}$ does not indicate the change over time of unemployment rate, but the contribution to the growth in MDLS that is explained by the change in unemployment rate. 
Table 2. List of independent variables used in regression analysis

\begin{tabular}{ll}
\hline Variables & Description \\
\hline log income & Natural logarithm of household disposable income \\
unemployment rate & Unemployment rate \\
life expectancy & Life expectancy at birth \\
equality & 1 - income inequality factor (from the general mean function of MDLS) \\
elderly rate & Dependency Ratio, Elderly (\% 65+ over population 15-64) \\
industry & Share of workers in the industrial sector (B-E) \\
workers in industry & Share of labour force with tertiary educational attainment \\
tertiary education & Differential between average participation rate and female participation rate \\
gap participation rate & 1 if highest share of population live in large cities (>1.5M) \\
voters turnout & Voters turnout \\
broadband access & Share of households with access to broadband connection \\
highways & Density of highways (km of highways over population) \\
doctor rate & Number of physicians per 1 000 inhabitants \\
\hline
\end{tabular}

33. Policy variables include access to services, road infrastructure and percentage of medical doctors per 1000 inhabitants. Access to services is a complex concept, which can be articulated and measured in many different ways. In this analysis, access to services is measured by the share of households having access to broadband connection, consistently with the OECD Regional Well-being framework (OECD, 2014) and its related database. The stock of road infrastructure is instead measured by the length of highways (in kilometres) per capita. It is worth mentioning that this latter variable might overestimate the true access to infrastructure in large sparsely populated regions, which might have relatively high numbers of kilometres of highway per capita. All specifications include country fixed effects, which account for non-observable country-specific factors, which might be related to economic, cultural or institutional characteristics.

34. Regression results are reported in Table 3 and are derived by estimating equations 1-4 jointly by applying Seemingly Unrelated Regression Estimation (SURE) procedures. Results show that all the components of MDLS growth display a convergence pattern, i.e. the contribution of each dimension was higher the lower the initial level of outcome considered, though in the case of health the coefficient is not statistically significant. Income growth is positively associated with a higher share of workforce with tertiary education and with a lower gap between the average and the female participation rate in the labour market. A higher elderly dependency rate is negatively associated with life expectancy and positively with the contribution of jobs to MDLS. The latter association might reflect that regions with relatively higher shares of retired people and people out of the labour force were relatively less sensitive to the crisis and to its impact on jobs outcomes. A relatively higher share of employment in the industrial sector is associated with worse health outcomes, possibly suggesting the existence of environmental risks in the production places (i.e. heavy industries).

35. Metropolitan regions displayed on average higher increases of income inequality and a higher growth of health outcomes. The latter result confirms those by Singh and Siahpush (2014) who found that the gap in life expectancy between urban and rural areas further increased during the last few decades. 
Table 3. Regression results

\begin{tabular}{|c|c|c|c|c|}
\hline & \multicolumn{4}{|c|}{ Dependent variables } \\
\hline & $\begin{array}{l}\text { Growth of } \\
\text { income }\end{array}$ & $\begin{array}{l}\text { Contribution of } \\
\text { jobs to MDLS } \\
\text { growth }\end{array}$ & $\begin{array}{c}\text { Contribution of } \\
\text { health to } \\
\text { MDLS growth }\end{array}$ & $\begin{array}{c}\text { Contribution of } \\
\text { equality to } \\
\text { MDLS growth }\end{array}$ \\
\hline $\log$ income & $-4.030^{* * *}$ & & & \\
\hline unemployment rate & & $0.122^{* * *}$ & & \\
\hline life expectancy & & & -0.035 & \\
\hline equality & & & & $-9.661 * * *$ \\
\hline elderly rate & -0.026 & $0.054 * * *$ & $-0.039 * * *$ & 0.012 \\
\hline workers in industry & -1.714 & 1.505 & $-2.254 * * *$ & $2.349 * * *$ \\
\hline tertiary education & $0.079 * * *$ & $0.038^{* *}$ & -0.005 & -0.007 \\
\hline gap participation rate & $-0.122 * * *$ & $-0.090^{* * *}$ & -0.008 & 0.000 \\
\hline metro regions & -0.159 & -0.132 & $0.162^{* * *}$ & $-0.355^{* * *}$ \\
\hline broadband access & 0.033 * & -0.001 & $-0.010 * *$ & $0.017 * *$ \\
\hline highways & -0.040 & 0.136 & & -0.050 \\
\hline voter turnout & & & $0.011 *$ & 0.013 \\
\hline doctor rate & & & $0.117^{* * *}$ & \\
\hline intercept & $39.631^{* * *}$ & $-3.792^{* \star \star}$ & $5.400^{* * \star}$ & $6.074 * * *$ \\
\hline N. obs. & 172 & 172 & 172 & 172 \\
\hline R-squared & 0.809 & 0.758 & 0.866 & 0.402 \\
\hline Country fixed effects & yes & yes & yes & yes \\
\hline
\end{tabular}

36. Regarding the policy variables, access to broadband services is positively associated with income growth, which in turn, as shown in the previous section, is the major driver of MDLS. Regions with higher share of household with broadband access also show relatively lower increases in health outcomes and higher reductions in income inequality. Health outcomes are positively associated to the number of doctors per capita and voters' turnout, as expected. All these correlations suggest potential channels through which policies designed and implemented at different levels of government can affect people's living standards. Analysing the specific effects of the various domains of policy was not the objective of this paper, thus the answer to such a question is left to further research.

\section{Concluding remarks}

37. MDLS provide a measure of welfare improvements that account for both levels and distributions of different well-being outcomes (OECD, 2014a; 2014b). Such a measure allows identifying the estimated contribution of each dimension to the overall change in living standards and it can be relevant for policy makers in order to identify existing trade-offs and synergies between different sectoral policies.

38. This paper provides novel evidence on the levels and trends of MDLS at regional level for a subset of OECD countries. The measurement of MDLS at regional level has a wider meaning than a simple application of the methodology at a different geographical scale. Many of the important interactions among sectoral policy are place-specific and hence particularly relevant at the sub-national scale. The determinants of school drop-out rates, for example, can be very different between urban and rural areas. Similarly, different regions within the same countries might face different challenges in terms of improving environmental outcomes, extending access to services and leveraging policy synergies, tailored on their specific needs. 
39. However, there are elements of the measurement of MDLS that can be subject of criticism, especially when applied at the sub-national scale. First, the focus on the specificities of places might require accounting for potential differences in preferences across regions. This would imply different sets of shadow prices by region rather than a homogenous set of shadow prices for the whole OECD. Data availability on subjective well-being at regional level is however a major constraint in this respect. Second, the estimation of shadow prices at regional level should probably include well-being dimensions that are particularly relevant locally, such as environment, access to services and safety outcomes. These extensions are left out of this paper, but represent promising issues for further work in this area. 


\section{REFERENCES}

Alesina, Di Tella, R., MacCulloch, R. (2004), "Inequality and happiness: are Europeans and Americans different?”, Journal of Public Economics 88, pp. 2009-2042.

Ambrey, C.L. and C.M. Fleming (2013), "Public Green Space and Life Satisfaction in Urban Australia", Urban Studies doi: 10.1177/0042098013494417

Atkinson, A.B. (1970), “On the Measurement of Inequality”, Journal of Economic Theory, Vol. 2, pp. 319328.

Bassanini, A. and R. Duval (2006), "Employment Patterns in OECD Countries: Reassessing the Role of Policies and Institutions", OECD Economics Department Working Papers, No. 486, OECD Publishing.

Behrens, K., G. Duranton and F. Robert-Nicoud (2014), "Productive Cities: Sorting, Selection, and Agglomeration", Journal of Political Economy, Vol. 122(3), pp. 507-553.

Boarini, R., M. Comola, C. Smith, R. Manchin, F. de Keulenaer, (2012), "What Makes for a Better Life?: The Determinants of Subjective Well-Being in OECD Countries - Evidence from the Gallup World Poll”, OECD Statistics Working Papers, 2012/03, OECD Publishing, http://dx.doi.org/10.1787/5k9b9ltjm937-en

Causa, O., A.de Serres, and N. Ruiz (2014), "Can pro-growth policies lift all boats? An analysis based on household disposable income", OECD Economics Department Working Paper, No. 1180, December 2014.

Chetty, R.D., N. Hendren, P. Kline, E. Saez (2014), "Where is the land of opportunity? The geography of intergenerational mobility in the United States", The Quarterly Journal of Economics, 129(4), pp. $1553-1623$.

Clark, A.E. and C. Senik (2011), "Will GDP Growth Increase Happiness in Developing Countries?," IZA Discussion Papers 5595, Institute for the Study of Labor (IZA).

Cutler, D. and A. Lleras-Muney (2008), "Education and Health: Evaluating Theories and Evidence", in J House, R Schoeni, G Kaplan and H Pollack (eds.), Making Americans Healthier: Social and Economic Policy as Healthpolicy, Russell Sage Foundation, New York.

Decancq, K., M. Fleurbaey, E. Schokkaert (2015), “Inequality, Income, and Well-Being”, Handbook of Income Distribution, Volume 2A, Elsevier, pp. 73-140.

D'Costa, S. and H. Overman (2014), “The urban wage growth premium: Sorting or learning?", Regional Science and Urban Economics, 48, pp. 168-179.

Eriksson, M. (2011), "Social capital and health - implications for health promotion", Global Health Action, Vol. 4, http://dx.doi.org/10.3402/gha.v4i0.5611

Ferreira, S. and M. Moro (2010), "On the use of subjective well-being data for environmental Valuation", Environmental and Resource Economics, 46, pp. 249-273. 
Fesseau, M. and P. Van de Ven (2014), "Measuring inequality in income and consumption in a national accounts framework", OECD Statistics Brief, November, No.19.

http://www.oecd.org/std/na/Measuring-inequality-in-income-and-consumption-in-a-nationalaccounts-framework.pdf

Frey, B., S. Luechinger, A. Stutzer (2009), "The Life Satisfaction Approach to Valuing Public Goods: the Case of Terrorism", Public Choice, 138(3), pp. 317-345.

Jolliffe, D. (2006), "Poverty, Prices, and Place: How Sensitive Is the Spatial Distribution of Poverty to Cost of Living Adjustments?", Economic Inquiry, Vol. 44, No. 2, pp. 296-310.

Maynou, L., M. Saez, J. Bacaria, G. Lopez-Casasnovas (2015), "Health inequalities in the European Union: an empirical analysis of the dynamics of regional differences", The European Journal of Health Economics 16(5), pp. 543-559.

Mincer, J. (1993), "Education and Unemployment", in Collected Essays of Jacob Mincer, Volume 1, Studies in Human Capital. Elgar, London.

Morrison, P.S. (2011), "Local Expressions of Subjective Well-being: The New Zealand Experience", Regional Studies 45.8, pp. 1039 -1058.

Murtin, F., R. Boarini, J. Cordoba, M. Ripoll (2015). "Beyond GDP: Is There a Law of One Shadow Price?", OECD Statistics Working Papers 2015/05, OECD Publishing, Paris. http://dx.doi.org/10.1787/5jrqppxzss47-en

OECD (2006), Measuring the Effects of Education on Health and Civic Engagement - Proceedings of the Copenhagen Symposium, OECD Publishing, Paris. http://www.oecd.org/edu/innovationeducation/37437718.pdf

OECD (2010), Social Capital, Human Capital and Health: What is the Evidence?, OECD Publishing, Paris. http://www.oecd.org/edu/research/45760738.pdf

OECD (2011), How's Life - Measuring Well-being, OECD Publishing, Paris.

OECD (2011b), OECD Regional Outlook 2011: Building resilient regions for stronger economies, OECD Publishing. http://dx.doi.org/10.1787/9789264120983-en

OECD (2012), "Measuring the access to public services: the case of public hospitals", paper presented at the OECD Working Party on Territorial Indicators, Paris 3 December.

OECD (2012b), Redefining “urban”. A new way to measure metropolitan areas, OECD Publishing, Paris. http://dx.doi.org/10.1787/9789264174108-en

OECD (2013), Regions at a Glance, OECD Publishing, Paris.

OECD (2014), How's Life in Your Region. Measuring Regional and Local Well-being for Policy-making, OECD Publishing, Paris.

OECD (2014a), All on Board. Making Inclusive Growth Happen, OECD Publishing, Paris.

OECD (2014b), Changing the Conversation on Growth. Going Inclusive, OECD and Ford Foundation Publishing, Paris. 
OECD (2014d), OECD Regional Outlook 2014: Regions and Cities: Where Policies and People Meet, OECD Publishing. http://dx.doi.org/10.1787/9789264201415-en

OECD (2015a), In It Together: Why Less Inequality Benefits All, OECD Publishing, Paris. http://dx.doi.org/10.1787/9789264235120-en

OECD (2015b), Economic Policy Reforms 2015: Going for Growth, OECD Publishing, Paris. http://dx.doi.org/10.1787/growth-2015-en

OECD (2015c), How's Life 2015, OECD Publishing, Paris.

Piacentini, M. (2014), "Measuring Income Inequality and Poverty at the Regional Level in OECD Countries", OECD Statistics Working Papers, 2014/03, OECD Publishing. http://dx.doi.org/10.1787/5jxzf5khtg9t-en

Rehdanz, K., Maddison, D. (2005), “Climate and happiness”, Ecological Economics, vol. 52(1), pp. 111125.

Rothwell, J.T., Massey, D.S. (2015), “Geographic Effects on Intergenerational Income Mobility”, Economic Geography, 91(1), pp. 83-106.

Royuela, V., P. Veneri and R. Ramos (2014), "Income Inequality, Urban Size and Economic Growth in OECD Regions”, OECD Regional Development Working Papers, 2014/10, OECD Publishing. http://dx.doi.org/10.1787/5jxrcmg8818r-en

Sen, A. (1999), Development as Freedom, Knopf, New York.

Singh, G.K. and M. Siahpush (2014), "Widening Rural-Urban Disparities in Life Expectancy, U.S., 19692009", American Journal of Preventive Medicine, Vol. 46, No. 2, pp. e19-e29. DOI: http://dx.doi.org/10.1016/j.amepre.2013.10.017

Stevenson, B., and J. Wolfers (2008), "Economic Growth and Subjective Well-Being: Reassessing the Easterlin Paradox", Brookings Papers on Economic Activity, Spring.

Strulik, H. (2013), "Preferences, income, and life satisfaction: An equivalence result", Center for European, Governance and Economic Development Research Discussion Papers 171, University of Goettingen, Department of Economics.

Verme, P. (2011), "Life Satisfaction and Income Inequality", The Review of Income and Wealth 57(1), pp. 111-137.

White, M.P. et al. (2013), "Would you be happier living in a greener urban area? A fixed-effects analysis of panel data", Psychological Science, Vol., 24, No. 6, pp. 920-928.

World Bank (2015), A Measured Approach to Ending Poverty and Boosting Shared Prosperity: Concepts, Data, and the Twin Goals, Policy Research Report, World Bank, Washington, DC, http://elibrary.worldbank.org/doi/book/10.1596/978-1-4648-0361-1 (accessed 10 June 2015). 


\section{APPENDIX 1: SOURCES OF INCOME DISTRIBUTION DATA}

Table A1. Data sources for income distribution at regional level

Quintiles of equivalised household income

\begin{tabular}{|l|l|l|l|}
\hline Country & Data source & Waves & $\begin{array}{l}\text { Number } \\
\text { regional } \\
\text { units (TL2) }\end{array}$ \\
\hline Belgium & European Union Statistics on Income and Living Conditions (EU-SILC) & $2004-2011$ & 3 regions \\
\hline Canada & Survey of Labour and Income Dynamics (SLID) & $2004-2011$ & 10 regions \\
\hline Chile & Encuesta de Caracterización Socioeconómica Nacional (CASEN) & $2003-2013$ & 15 regions \\
\hline Czech Republic & European Union Statistics on Income and Living Conditions (EU-SILC) & $2005-2013$ & 8 regions \\
\hline Estonia & European Union Statistics on Income and Living Conditions (EU-SILC) & $2004-2013$ & 1 region \\
\hline Finland & European Union Statistics on Income and Living Conditions (EU-SILC) & $2004-2013$ & 4 regions \\
\hline France & European Union Statistics on Income and Living Conditions (EU-SILC) & $2004-2013$ & 22 regions \\
\hline Greece & European Union Statistics on Income and Living Conditions (EU-SILC) & $2004-2013$ & 4 regions \\
\hline Italy & Indagine sulle condizioni di vita (UDB IT SILC) & $2004-2013$ & 21 regions \\
\hline Korea & Korean Labour \& Income Panel Study (KLIPS) & $2004-2013$ & 6 regions \\
\hline Luxembourg & European Union Statistics on Income and Living Conditions (EU-SILC) & $2004-2013$ & 1 region \\
\hline Mexico & Encuesta Nacional de Ingreso y Gastos de los Hogares (ENIGH) & $2004-2012$ & 32 regions \\
\hline Spain & European Union Statistics on Income and Living Conditions (EU-SILC) & $2004-2013$ & 19 regions \\
\hline United Kingdom & European Union Statistics on Income and Living Conditions (EU-SILC) & $2010-2013$ & 12 regions \\
\hline & & $2002-2003-2004$ & \\
United States & Current Population Survey (CPS) & (average); & $2011-$ \\
& & $2012-13$ (average) & regions \\
\hline
\end{tabular}

Note: No Institute of Statistics or organisation making data available for the computation of regional income statistics have any responsibility for the results and conclusions reported in this work. 


\section{APPENDIX 2: CALIBRATION OF THE AVERSION TO INEQUALITY PARAMETER FOR THE COMPUTATION OF INCOME STANDARDS}

40. This Appendix attempts to identify the value of the parameter of aversion to inequality $(\tau)$ to be used in the Atkinson function when aggregating the equivalent income of the different income groups. To be reminded that, at regional level, income groups are identified by looking at the quintiles of the distribution of household disposable income within each region.

41. By changing the value of $\tau$ we implicitly assign a different weight to a certain part of the income distribution. In order to identify $\tau$ in order to target a specific income groups, it is necessary to compute income standards by using many values of the parameter within a certain interval and select the value that yields the level of income standards which is the closest to the level of income of the reference group.

42. The first step is to define the Atkinson function to compute the income standards:

$$
I S_{i}=\left(\frac{1}{5} \sum_{d}^{5} y_{d, i}^{1-\tau}\right)^{\frac{1}{1-\tau}}
$$

where $I S_{i}$ is the income standards of the $i$-th region, $y_{d, i}$ is the disposable household income of the $d$-th quintile in the $i$-th region as computed in and $\tau$ is the parameter that reflects the society's aversion to inequality. By definition, the aversion to inequality increases as $\tau$ increases. In other words, by increasing $\tau$ the function will yield a lower income.

43. The income groups for which we show the closest value of $\tau$ are the median household, the bottom $40 \%$ and the bottom $20 \%$, which are identified with the $50^{\text {th }}, 40^{\text {th }}$, and $20^{\text {th }}$ percentiles of the income distribution, respectively.

44. Figure A.1 shows the distribution of $\tau$ parameter when the target groups are the median household and the bottom 40\%. Table A.2 reports instead the mean values of the $\tau$ parameter for the same target groups, both for the whole sample of regions and by country. Regions are considered twice - one point for the first and the last year available, respectively - for a total of 418 observations (209 OECD TL2 regions).

Figure A.1. Distribution of the aversion to inequality parameter according to the targeted income group

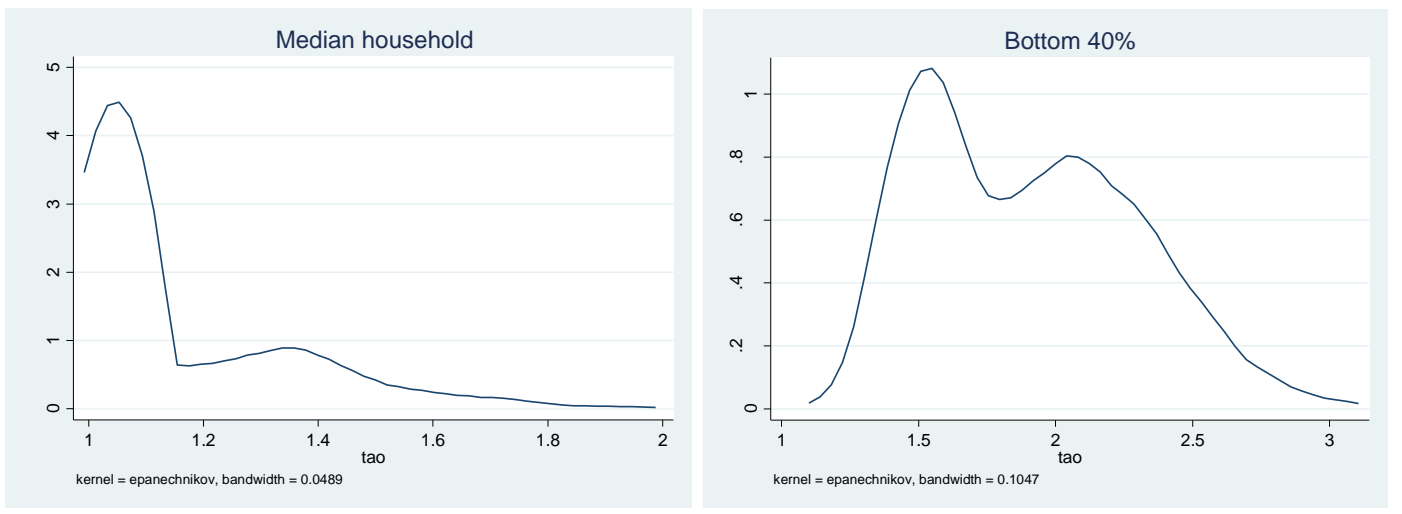


Table A.2. Mean aversion to inequality parameter according to the targeted income group, by country

\begin{tabular}{lrr}
\hline Country & Median household & Bottom $40 \%$ \\
\hline BEL & 1.16 & 2.07 \\
CAN & 1.04 & 1.63 \\
CHL & 1.33 & 2.06 \\
CZE & 1.26 & 2.43 \\
ESP & 1.06 & 1.67 \\
EST & 1.04 & 1.84 \\
FIN & 1.07 & 2.31 \\
FRA & 1.26 & 2.35 \\
GBR & 1.14 & 2.08 \\
GRC & 1.04 & 1.72 \\
ITA & 1.06 & 1.85 \\
KOR & 1.05 & 1.56 \\
LUX & 1.08 & 2.29 \\
MEX & 1.39 & 2.21 \\
USA & 1.04 & 1.51 \\
& & \\
Mean & 1.16 & 1.90 \\
Std. dev. & 0.19 & 0.39 \\
\hline
\end{tabular}

45. The values of the $\tau$ parameters by country show that regions in Chile, Czech Republic, France and Mexico have on average substantially higher parameters than in the other regions when the median household is the reference income group. On the other hand, when the bottom $40 \%$ is taken into account, there is a higher variability across regions in the values of the $\tau$ parameters, with Finland and France having the highest values, on average.

46. When the target group is the bottom 20\%, then by construction $\tau$ is equal to the higher bound of the possible values, since information on the income distribution within regions are given by quintile and the lowest percentile available corresponds to the household identifying the bottom $20 \%$ of income. As a consequence, and for consistency with the Inclusive Growth framework at national level, when the target group is the bottom $20 \%$ of income, $\tau$ is set to the value of 50 . 


\section{APPENDIX 3. MDLS GROWTH IN OECD REGIONS: CONTRIBUTION BY DIMENSIONS}

Figure A.2. Relative contribution of household income, longevity, unemployment and income inequality to changes in multidimensional living standards, around 2003-2012

Percentages
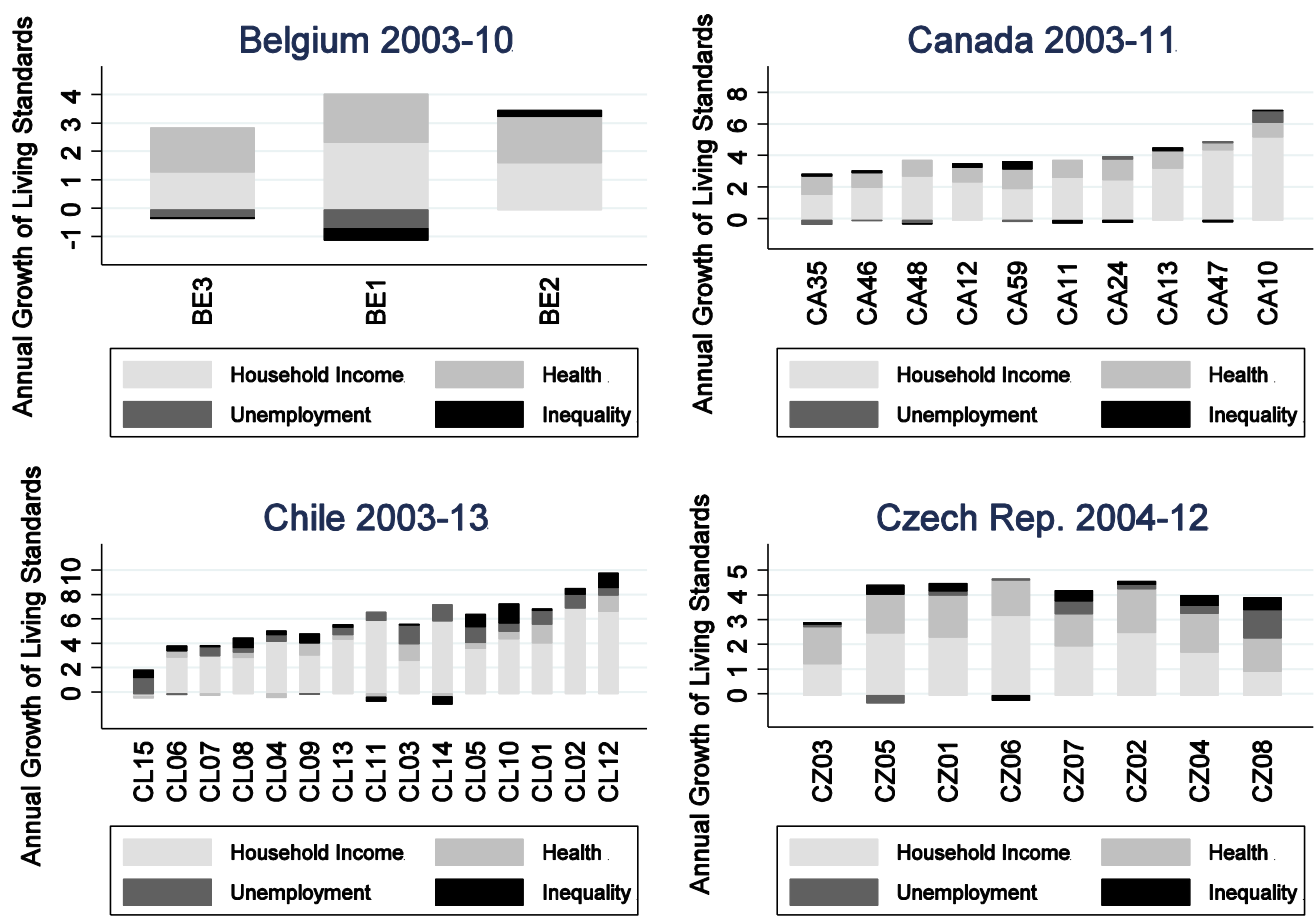

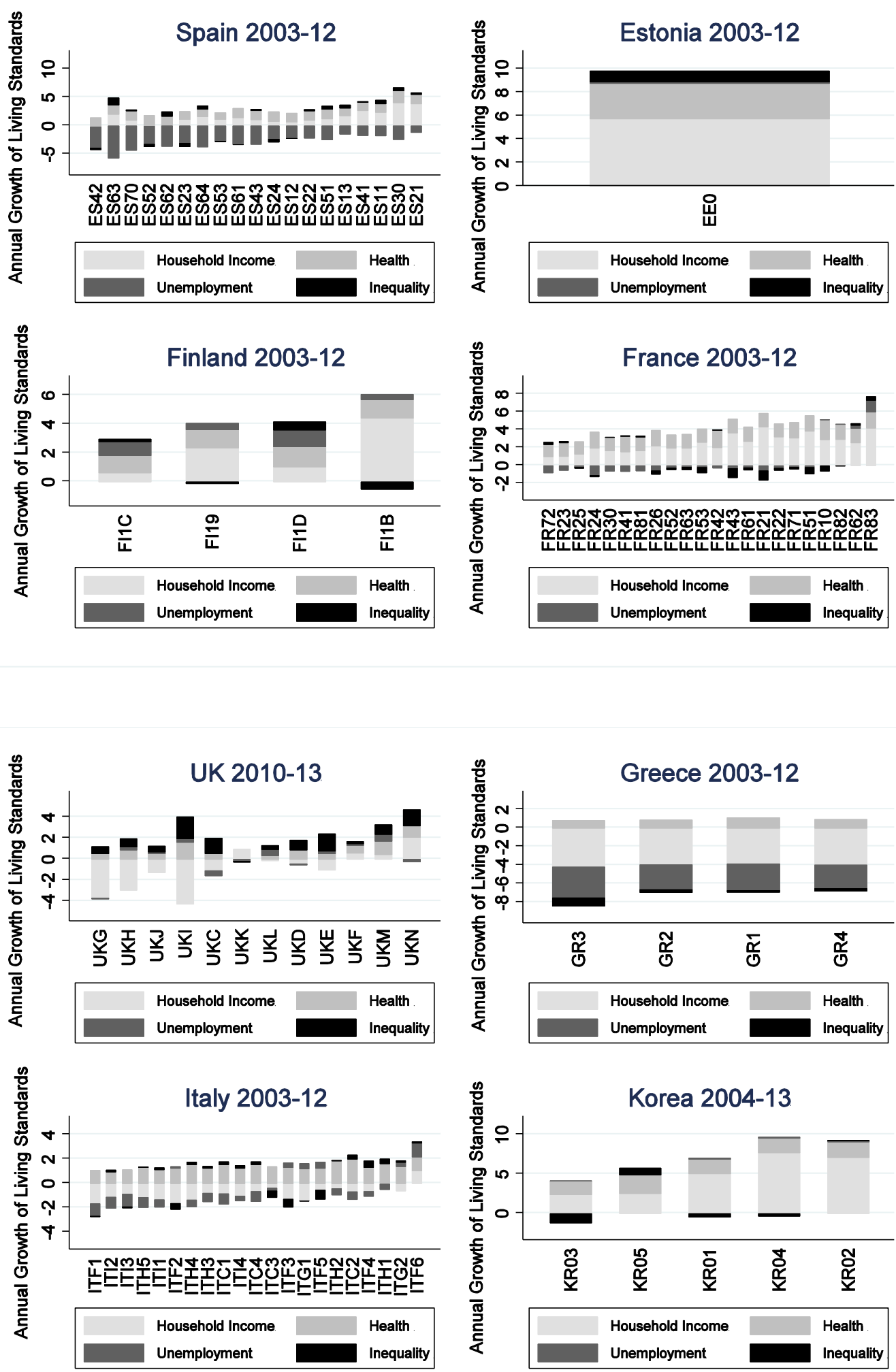

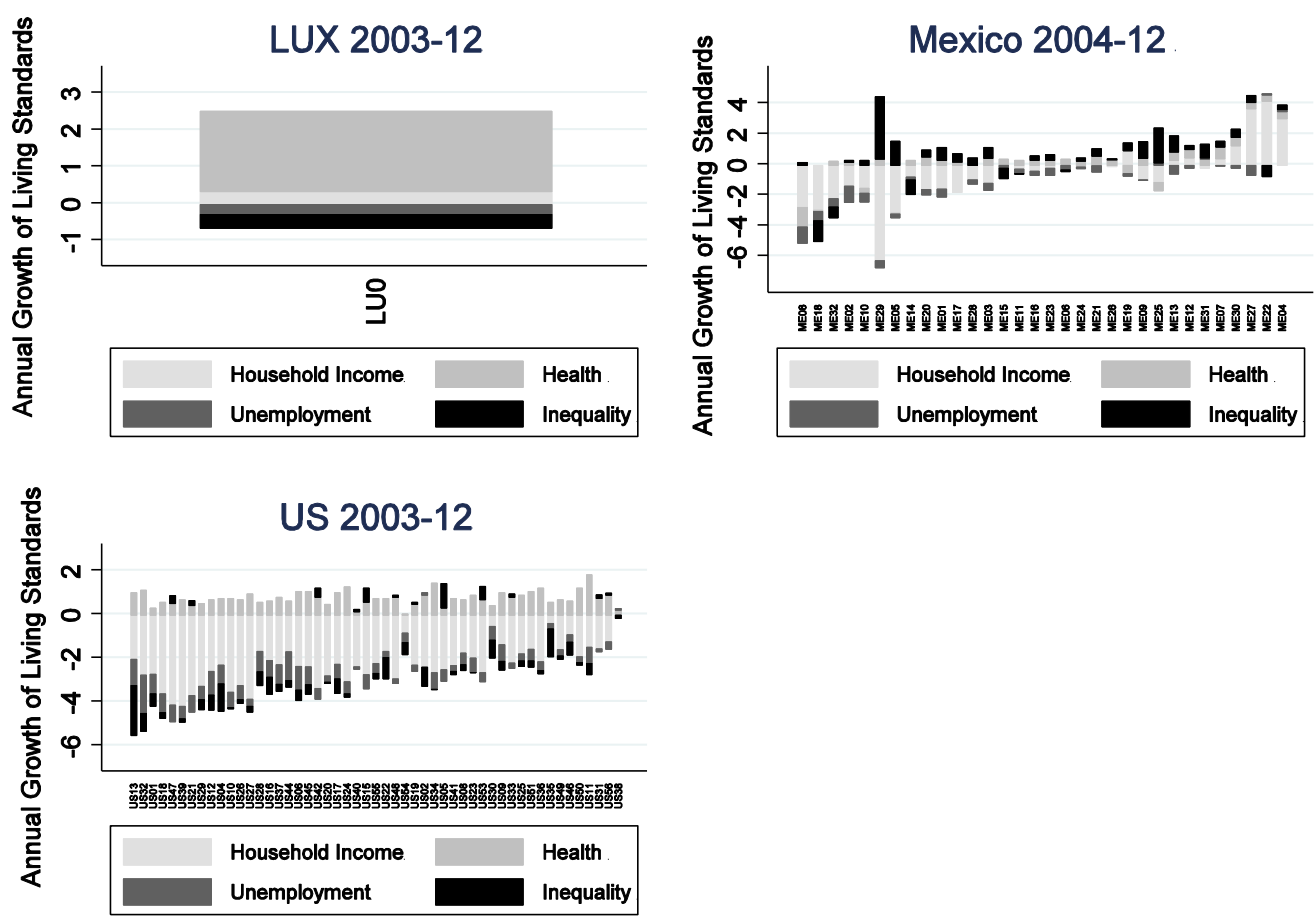